\title{
Traduções
}

\section{Sisterna Mundial e Inter-Relacionamento de Redes: a Internacionalização da Educação e o Papel da Pesquisa Comparativa}

\section{Jurgen Schriewer}

Institut fur Allgemeine Pádagogik/Philosophische Fakultàt IV/HumboldtUniversitàt zu Berlin

\section{Internacionalização: processo e problema}

Internacionalização originou-se de um termo de direito internacional $^{1}$. Como tal, é empregado desde o século XIX para se referir às limitações da soberania do Estado sobre todo ou parte do território nacional, por exemplo, cidades importantes, hidrovias ou portos, favorecendo outros estados ou a comunidade internacional como um todo ${ }^{2}$. Somente após 1945, aparentemente associado à criação das Nações Unidas, o termo assumiu um significado mais geral.

Internacionalização, como o seu correspondente mais recente, globalização, é usado cada vez mais para descrever tendências à

\footnotetext{
${ }^{1}$ Este artigo apresenta uma linha de raciocinio que foi desenvolvida pela primeira vez na minha conferência inaugural proferida na Universidade Humholdt, Berlim, dezembro de 1992. Expresso a minha gratidão a Edwin Keiner, da Universidade de Frankfurt, e aos participantes da Conferência Internacional sobre a Mudança das Relações entre o Estado, a Sociedade Civil e a Comunidade Educacional, na Universidade de Wisconsin Madison, junho de 1993, por seus valiosos comentários sobre a primeira versão deste trabalho. Gostaria de agradecer especialmente a Jack Michael Halverson, Universidade Humboldt, cujos comentarios pertinentes e habilidades lingüísticas tornaram possível uma versão em inglês.

${ }^{2}$ Compare, por exemplo, o verbete "Intemaciolização" na Encyclopaedia Universalis, Thesaurus (Paris: Encyclopaedia Universalis, 1990), p. 1774.
} 
intensificação das relações globais de interação e intercâmbio, a interligação mundial dos campos da comunicação social e a harmonização dos modelos e estruturas sociais (ver McGrew, 1992). Internacionalização e globalização referem-se a uma realidade social que cada vez mais também se estende às experiências cotidianas dos indivíduos, na forma de interligações financeiras internacionais e das crises monetárias; das interdependências ecológicas mundiais; dos crescentes custos sociais de um turismo de massa, que está se espalhando ao redor do globo; das pressões das migrações globais, ou da intensificação imprevista da transmissão mundial de notícias. Embora essas ou outras relações de interdependência global pareçam familiares a observadores contemporâneos, a mudança recente no uso do termo internacionalização indica que, da perspectiva da macrossociologia histórica, os processos mencionados acima são, "em termos evolutivos, um fenômeno totalmente novo" (Luhmann, 1975a, p.57).

Tendências à internacionalização e à globalização também se verificam em áreas da interação social tão cruciais para as sociedades modernas como os subsistemas sociais para a educação e o treinamento, isto é, as organizações de grande porte, amplamente desenvolvidas, das escolas e universidades, incluindo os esforços de controle e reflexão voltados para esses sistemas na forma de políticas educacionais, planejamento, pesquisa e teoria. Desse modo, não há nenhuma falta de diagnósticos afirmando que

como na vida econômica, a interligação internacional na educação tem se fortalecido cada vez mais como conseqüência do domínio atual do espaço. Coerentemente, os elos internacionais entre educadores atualmente são tão estreitos, as trocas tão intensas, que é possível falar de um público educacional mundial.

Afirmações como essas poderão exemplificar bem uma consciência maior do fato de que a comunicação educacional tem se tornado globalizada. Entretanto, o trecho citado não surgiu no contexto de um debate recente. Foi tirado de um tratado publicado há mais de sessenta anos com o título 
ambíguo de Internationale Padagogik, Auslandspadagogik, Vergleichende Erziehungswissenschaft [Educação Internacional, Educação Estrangeira, Educação Comparativa (Schneider, 1931-1932, p.22)]. Com este tratado, Friedrich Schneider, no começo da década de 30, tentou concluir a incipiente institucionalização acadêmica da Educação Comparada na Alemanha, sobre alicerces firmes, tanto conceituais como metodológicos. Ele procurou abrir caminho para que o novo campo tomasse uma direção intelectual no seu subseqüente desenvolvimento como disciplina acadêmica, que mais devia atender ao universalismo supranacional do que à metodologia de análise transnacional. De acordo com essa teoria, a Internationale Zeitschrift für Eerziehungswissenschaft (Revista Internacional de Educação/Révue Internationale de Pédagogie), lançada por Schneider e inaugurada com o artigo supracitado, foi concebida como um meio de comunicação acadêmica que devia incentivar não só a pesquisa comparativa, interligando nações e sociedades, como também - conforme sugere o título - a internacionalização da consciência do problema pelos educadores e a edificação de uma teoria educacional.

Desse modo, a descrição das forças internacionalizantes na educação, que Schneider apresentou no começo da década de 30 , poderá ter se originado mais de uma intenção do que propriamente da análise racional da situação contemporânea. Nos meados da década de 90, em contraponto, essa descrição pôde ser confirmada por numerosos e diversificados indicadores como, por exemplo, a International Baccalaureate (Peterson, 1972) e a International Association for the Evoluation of Educational Achievement (Postlethwaite, 1987); as Conferências Internacionais sobre Educação, institucionalizadas há décadas em Genebra ${ }^{3}$,

\footnotetext{
${ }^{5}$ Levantamentos de dados e materiais estatísticos apresentados pelas delegações governamentais nacionais participantes dessas conferências foram publicados em números sucessivos do International Yearbook of Education. Conferir, por exemplo, os volumes de Educational Structures, preparados por Robert Cowen (v. 34/1982); Educational Development Trends, preparado por Brian Homes (v. 35/1983); Education for AU, preparado por Wolfgang Mitter (v. 36/1984); Technological Occupational Challenge, Social Transformation and Educational Response, preparado por Edmundo King (v. 37/1985); e Primary Education on theThreshold of the Twenty-first Century, preparado por José Luis Garcia Garrido (v. 38/1986). Para os desenvolvimentos recentes, ver o relatório de Hasselt e Schõfthaler. 1989.
} 
e a Conferência Mundial sôbre Educação para Todos, realizada em Jomtien, em 1990 (Unesco, 1992); programas mundiais de educação (Faure, 1972; Psacharopoulos, 1987) e World Crises Education (Coombs, 1985); World Education Indicators (Komenan, 1987) e Uma Consciência Mundial Pedagógica (Gelpi, 1992); a Enciclopédia Mundial de Educação (Kurian, 1988); di Enciclopédia Internacional da Educação (Husén, Postlethwaite, 1985); programas de cooperação bilaterais e multilaterais; Erasmus, Comett e Tempus, como também Cedepop e Eurydice ${ }^{4}$. Todos representam apenas parte de uma extensa rede de comunicação e cooperação internacional de educação.

Dado esse pano de fundo, um crescente número de vozes se levantaram a favor de alocar explicitamente a um determinado ramo de estudos educacionais as funções de refletir, apoiar e legitimar os processos de internacionalização tanto dos sistemas como da teoria educacional. Esse ramo é a Educação Comparada ou, como algumas pessoas preferem, conscientemente fazendo alusão às predileções de Schneider, Educação Internacional. $\mathrm{Na}$ forma desse ramo de estudos, argumentam, o processo da internacionalização da educação chega a se autoconscientizar. Entretanto, de acordo com a base lógica historicista subjacente a esse raciocínio, o campo da Educação Comparada e/ou Internacional, como a teoria que reflete este processo, reage no sentido do desenvolvimento avançado da "internacionalidade"

Este ponto de vista será discutido a seguir. É questionável até certo ponto - assim coloca o contra-argumento - , que a sua linha de raciocínio ignore fundamentalmente o antagonismo entre "internacional" o "comparado". Isto é, entre certas dimensões pertencentes ao domínio

\footnotetext{
${ }^{4}$ Resenhas informali vas dos programas da Comunidade Européia sobre políticas educacionais foram preparadas por Fahle (1989) e Müller-Solger (1990).

${ }_{5}^{5}$ Ver, por exemplo, a linha de raciocínio desenvolvida extensivamente por Kruger (1974), que abertamente se apoia na filosofia da história e por Anweiler (1977 e 1990), que na sua maior parte se refere ao anterior. Conclusões semelhantes foram extraídas, embora de diferentes pontos de vista por autores como Katz (1978) e DrSger(1991). Hufner, Meyer e Naumann (1987) oferecem uma descrição menos baseada no historicismo afirmativo do que nas ciências sociais analíticas.
} 
do objeto deste campo e um determinado método de análise, quer dizer, entre os processos socioculturais e "uma complexa abordagem de pesquisa"6 . Como conseqüência, essa posição desconsidera as distinções que Friedrich Schneider, com maior visão, já havia feito: isto é, a distinção entre as "conexões internacionais na educação" (como fato histórico) e a "Educação Internacional" (como campo de atividade intelectual) e, em relação a este último, a distinção entre "contemplação transnacional", com o enfoque de "expor os principais problemas, idéias e correntes da educação mundial" e a "análise transnacional", usada como método distinto para "descobrir afirmações gerais, que se assemelham às leis sobre educação" (Schneider, 1931, p.243). Entretanto, a colocação em questão promove, também, uma atitude intelectual que pretende enfatizar mais a confirmação, fazendo isto endossar a crescente intensificação das ligações globais implícitas no conceito da "internacionalização", que a elucidação analítica da complexidade dessas interligações.

O contra-argumento proposto, entretanto, não será desenvolvido somente em nível abstrato de crítica - nesse caso, metodológica. Ao contrário, tira vantagem das possibilidades oferecidas pela tão chamada mudança sociohistórica do discurso metacientífico (ver Pollak, 1983), para se fundamentar empiricamente e, desse modo, objetivar argumentos metodológicos. Mais precisamente, o que segue será orientado pelas teses nas quais Max Weber, no seu bem conhecido ensaio de 1904 sobre "objetividade" nas ciências sociais, evocou a historicidade fundamental das disciplinas acadêmicas e, em geral, da atividade científica:

De vez em quando, no percurso da especialização disciplinar e da normatização, Weber sugere que "a cor mudará: o significado dos pontos de vista adotados acriticamente torna-se incerto, o caminho desaparecendo no crepúsculo. A luz das questões centrais da civilização já foi embora. Como

* O método de comparação transcultural é assim caracterizado no volume 4, dedicado a Abordagens Complexas da Pesquisa do Handbook of Social Research, editado por Konig (1974). 
conseqüência, a ciência também se prepara para mudar sua posição e seu aparato conceitual e observar o fluxo dos eventos do alto da reflexão?

Desse modo, começarei por confrontar — de uma perspectiva baseada na história da ciência -—a emergência original da idéia de uma ciência comparada de educação com o questionamento daquele programa (Secção 1). Contra este pano de fundo, examinarei extensivamente as conclusões contrastantes da pesquisa (Secção 2), para considerar, finalmente, a questão da possível posição do campo ao final do século $\mathrm{XX}$ e em face de questões alteradas, ponto de vista e aparelhagens conceituais (Secção 3).

\section{Etapas}

FINAL DO SÉCULO XVIII ESBOÇO DE UM PROGRAMA ABRANGENTE

Para iniciar, descreverei rapidamente o contexto histórico que viu a emergência da idéia do estabelecimento de campos disciplinares de estudo, dedicados a uma pesquisa comparada da sociedade, do homem e da educação. Isto é ainda mais importante, ao contrário das interpretações arraigadas do desenvolvimento do campo, que focalizam quase exclusivamente os pioneiros individuais. $\mathrm{O}$ escopo do projeto de uma ciência comparada da educação, só se torna evidente contra o pano de fundo das transformações gerais da história da ciência que ocorreram ao final do século XVIII.

A introdução do método comparativo na ciência foi uma inovação no final do século XVIII e começo do século XIX. A pesquisa comparada,

\footnotetext{
7 "Irgendwann (im Verlauf einzelwissenschaftlicher Spezialisiening und Normalisierung) wechselt die Faroe: die Bedeutungder unreflektier verwerteten Gesichtspunkte wird unsicher, der Weg verliert sich in die Dãmmerung. Das licht der grossen Kulturprobleme ist weiter gezogen. Dann rustet sich auch die Wissenschaft, ihren Slandort und ihren Begriffsapparat zu wechseln und aus der Hõhe des Gedankens auf den Strom des Geschehens zu blichken" (Weber, 1973,p.214).
} 
naquele período, representou um non plus ultra na modernidade. Funcionou como um elemento essencial, projetando processos de reestruturação de longo alcance da ciência, descritos pela recente história da ciência como a "emergência de um moderno sistema de disciplinas acadêmicas" (Stichweh, 1984).

A transição da ciência pré-moderna à moderna envolveu uma reestruturação, acompanhada por uma radical reavaliação do conhecimento empírico. Em relação a isto, a abordagem comparada se insinuou como um meio, não apenas de gerar, mas também de analisar dados empíricos.

Nesse contexto histórico, o projeto que estabelece áreas acadêmicas dedicadas ao estudo comparado da linguagem, do direito, da religião, das constituições políticas e, eventualmente, da educação, é um dos primeiros e mais proeminentes exemplos da transferência de uma abordagem metodológica bem sucedida, oriunda das ciências naturais - especialmente da biologia - para as ciências humanas e sociais. Da mesma forma que Georges de Cuvier (1800-1805) fez um trabalho pioneiro, que marcou época para a anatomia, Anselm von Feuerbach (1810), um pouco mais tarde fez o mesmo para o estudo do Direito, e Franz Bopp, para a Lingüística (Lefmann, 1895, p. 115-118). $\mathrm{Na}$ área da educação o pioneiro foi Marc-Antoine Jullien de Paris (1817), que há mais de 175 anos esboçou o programa para transformar, mediante investigação empírica e análise comparada, uma soma heterogênea e não confirmada de conhecimentos numa disciplina distinta e cada vez mais autônoma. As "idéias normativas" — para empregar o termo usado por Max Weber — que lançaram a Educação Comparada tiveram por objetivo nada menos que a reformulação positivista das doutrinas educacionais, até então meramente especulativas, e o desenvolvimento da teoria educacional, na base da pesquisa metodologicamente conduzida. A própria originalidade desse texto de 1817, o mais antigo da língua francesa a usar o termo science 
de l'éducation (ciencia da educação), parte precisamente do fato de que se constituiu não apenas um manifesto a favor do estabelecimento da Educação Comparada, como também um programa para desenvolver uma Ciência da Educação como tal.

Foi nesse mesmo contexto histórico que se passou a dar importância aos subseqüentes problemas teóricos e metodológicos, associados à transferência da bem-sucedida abordagem da pesquisa biológica às ciências sociais e às humanidades. De fato, considerações desse tipo não apareceram nos trabalhos de Jullien, um personagem representativo do Iluminismo francês, que, após receber treinamento atualizado em zoologia comparativa, comprometeu-se principalmente com a reforma política e social. Entretanto, tais problemas receberam atenção nas reflexões de um estudioso de lingüística comparada, com treinamento em Filosofia, que, além de manter alto cargo na administração pública e no corpo diplomático, dedicou sua vida inteiramente ao estudo das humanidades. Refiro-me a Wilhelm von Humboldt e ao seu Plan einer vergleichenden Anthropologie (Esboço da Antropologia Comparada), publicado em 1795. Nesse tratado, Humboldt discutiu a questão metodológica sobre como mediar sistematicamente os objetos históricos (que formam o material empírico preexistente da antropologia) e o tratamento teórico desses objetos. Os últimos são orientados a captar as relações explicativas e a supor o conhecimento causal. Humboldt ainda considerou o problema teórico - a "peculiaridade", como ele o denominou - , encontrado pelas ciências sociais comparadas, exatamente pelo fato de que vai muito além do mundo da anatomia. Esse problema surge devido à diferença, fundamental para o objeto-domínio de todas as ciências sociais, entre as propostas "leis" da natureza humana e a "indispensável liberdade" do homem; entre as regularidades enraizadas no gênero humano e os sistemas sociais, tal como Humboldt (1964, p.36-42) chamou a energia espontânea do homem. Num sentido, Humboldt antecipou os debates contemporâneos sobre a teoria relacionada aos contrastes entre as relações causa-efeito em geral e à 
historicidade fundamental do homem, aberto a futuros desconhecidos, ou, em termos mais modernos, entre a causalidade e auto-referência.

Destacando essas duas ordens de problemas, Humboldt, ao mesmo tempo, apontou duas linhas de referência para os contínuos debates metodológicos que acompanharam o desenvolvimento da Educação Comparada como área acadêmica até hoje. Aqui não é o lugar para rever estes debates em detalhe, basta observar que, mesmo em condições de institucionalização acadêmica, a subdisciplina comparada ou "aspectodisciplina" (Diemer, 1970) da educação ficou embaraçada numa teia de expectativas conflitantes, designações funcionais contrastantes e opções metodológicas que são difíceis de serem reconciliadas (Schriewer, 1982; Epstein, 1983). As controvérsias resultantes surgem, por exemplo, da diferença entre as idéias amplamente sustentadas da Educação Internacional e as do programa clássico para a Educação Comparada. Elas surgem das expectativas conflitantes das políticas de pesquisa orientadas para a ação em face da reforma e da cientificidade orientada pela teoria. Ambas aparecem repetidamente em face da discrepância entre a prática amplamente divulgada de sintetizar as tendências internacionais de desenvolvimento para os fins de orientação e os requisitos de metodologia comparada, definidos de acordo com a lógica da descoberta científica. Mais recentemente, tais controvérsias resultam dos modos contrastantes de perceber o outro; do contraste que, por sua vez, é fundamental ao formar o distinto assunto da matéria de estudo, entre a minimização das diferenças culturais para facilitar a compreensão pragmática e a exploração integral dessas mesmas diferenças para os fins de análise das ciências sociais (Schriewer, 1990a).

\section{AO FINAI. DO SÉCULO XX! O MUNDO COMO UNIDADE DE ANÁLISE}

O que é radicalmente novo sobre a situação presente - a situação ao final do século XX - é o fato de que não mais se suscitam demandas de versões melhoradas da forma metodológica da Educação Comparada. 
Ao contrário, é questionada parte das pressuposições básicas, teóricas e metodológicas da área. $\mathrm{O}$ desenvolvimento recente da pesquisa e da teoria realmente dá conta da desimplicação do assunto-matèria da Educação Comparada, que em grande parte não é questionado: o mundo concebido como uma multidão de sociedades regionais ou nacionais que, como entidades autônomas, como configurações historicamente distintas, constituem o ambiente uma da outra. A conseqüência imediata de tal eliminação epistêmica do assunto-matèria da área é que seu procedimento metodológico definidor, como também a comparação aplicada à multiplicidade de unidades independentes de análise, são privados do seu significado. Então, a comparação é substituída por reconstruções históricas de processos de amplo alcance - processos de difusão cultural ou por análises globais de interdependência transnacional (McMichael, 1990; Wallerstein, 1976). Finalmente, duas diferentes correntes de lógica teórica coincidem em tais conclusões, isto é, respectivamente, a critica da teoria construída e os modelos do sistema mundial simulados.

O tipo de críticas à teoria aqui referida foi apresentado, entre outros, por Friedrich H. Tenbruck em 1981. O título do seu estudo Die Geburt der Gesellschaft ansdemGeist der Soziologie (O Nascimento da Sociedade Oriundo do Espírito da Sociologia) resume as suas teses. De acordo com Tenbruck, se a formação de uma rede de comunicação, que é especificamente sociológica, pode ser concebida como sendo uma resposta intelectual a uma realidade social radicalmente nova que emergiu, ao final do século XVIII e início do século XIX, desde a dissolução das estruturas sociais corporativistas, baseadas no Estado, no começo da Europa moderna, então, a concepção de uma sociedade subseqüentemente favorecida por aquele discurso sociológico - isto é, o conceito abstrato de uma multiplicidade de sociedades mutuamente independentes, quase autárquicas e até certo ponto comparáveis - é limitada pelo contexto em diversos aspectos e, portanto, possui validade teórica questionável. Tenbruck (1981, p.348) relata ainda que esse conceito de sociedade não 
tinha apenas a chancela dos requisitos teóricos de uma disciplina, que se espelhava em modelos das ciências naturais, mas também assumiu como imutável um certo estado contemporâneo das coisas, meramente transitório, quer dizer, uma auto-imagem das nações do século XIX, concernente à sua individualidade cultural e autonomia política, para a qual a identidade do povo, da cultura, da nação e do Estado ofereceram uma lição clara da história. Porém, continua Tenbruck, o conceito de sociedade com aquela pretensão deveria, de fato, ter sido falsificado, há tempos, pelo fenômeno da internacionalização e pelos processos em grande escala de difusão transcultural.

O que faz essas teses serem bastante pontuais, no seu antagonismo à abordagem comparada, é - além da sua reanálise da história social e intelectual - o fato de que Tenbruck as desenvolveu por meio de uma intensa discussão das obras de Emile Durkheim. Ao repudiar Durkheim, ele, ao mesmo tempo, repudia o único teórico das ciências sociais comparadas que, mais que qualquer outro, foi o responsável pela tradução, ao final do século XIX, do programa abrangente do fim do século XVIII e por transformá-lo em rigorosa metodologia científica. Assim procedendo, Durkheim também demonstrou que o método comparado era o substituto - especialmente adequado às ciências sociais — para os experimentos macrossociais, assim colocando os alicerces para a tradição da pesquisa da ciência social, que continua a ser de crucial importância até os dias de hoje. Basta recordar aqui o bem conhecido texto das Regras do Método Sociológico (publicado pela primeira vez em 1895), de Durkheim, onde ele assume a idéia concebida durante o período da ampla reestruturação da ciência, um século antes. Ele reitera a ligação entre a pesquisa comparada e a formação de disciplinas científicas:

A Sociologia comparada não é meramente um ramo especial da Sociologia. Melhor dizendo, é idêntica à própria Sociologia quando deixa de ser puramente descritiva e tem por objetivo relatar os fatos (Durkheim, 1986, p.137). 
Enquanto reconstruções críticas da teoria social têm sido historicamente relativizadas, não apenas as pressuposições básicas em relação ao assunto-matèria especificó, mas também o projeto das ciências sociais comparadas, esse projeto está sendo alcançado - em termos da teoria evolucionaría - dentro do arcabouço das análises do sistema mundial. Da mesma forma que a sociologia clássica se viu como resposta à realidade social do século XIX, modelos do sistema mundial, por sua vez, reivindicam que macroestruturas sociais do fim do século XX possam ser captadas adequadamente apenas quando se leva em consideração o contexto global das relações mundiais da interdependência, que se intensificaram de diversas maneiras (So, 1990, p.269). Também esta reivindicação se estende à análise de áreas especiais, tais como os sistemas nacionais de educação. Essas estruturas, com potencial para desenvolvimento, e as funções sociais, argumenta-se, podem ser explicadas apenas se suas respectivas posições, numa estrutura mundial, são levadas em consideração sistematicamente:

As análises da educação, no contexto de sistemas nacionais fechados, não conseguem captar a posição de um país no sistema internacional. E esta situação que condiciona os efeitos de fatores econômicos, políticos e socioculturais intranacionais sobre o desenvolvimento ou o subdesenvolvimento educacional... Essa perspectiva global amplia o nosso entendimento das origens, evolução e implicações das práticas educacionais, combinando níveis micro e macro de análise e vinculando ocorrências regionais aos eventos nacionais e internacionais (Amove, 1980, p.50 e 54).

A elaboração da teoria, considerando os parâmetros decisivos para a construção de modelos do sistema mundial, está, no momento, incompleto (ver Bornschier e Lengyel, 1990, p.3-15):

- O trabalho predominante nesta área tem tomado forma como resultado da retomada por Wallerstein das investigações braudelianas em história econômica (isto é, um processo amplamente concebido a longo prazo que analisa em grande escala redes de relações de intercâmbio 
transcontinentais), trabalho interpretado à luz da economia política do capitalismo e da teoria da dependência (Braudel, 1979; Wallerstein, 1976 e 1991).

- Modelos que usam argumentos que não são tanto economicistas e, sim, baseados na teoria da modernização e na sociologia cultural, desenvolvidos por um grupo de pesquisa liderado por John W. Meyer e Francisco Ramirez, em Stanford, focalizam a universalização dos padrões organizacionais e socioculturais, em particular, da Nação-Estado (Meyer, Hannan, 1979; Boli-Bennetti, Ramirez, Meyer, 1986).

- Conceituações baseadas na teoria da diferenciação social procuram explicar, eventualmente, a emergência da sociedade mundial em termos da dinâmica intrínseca aos subsistemas funcionalmente específicos da sociedade - especialmente a economia e a pesquisa científica -, que tendem a intensificar seus elos especiais de comunicação, independentemente das limitações dos sistemas políticos, territorialmente organizados (Luhmann, 1975a e 1982a).

A seguir, a idéia básica do sistema mundial, como paradigma, será caracterizada em relação a uma versão teórica, cujas origens remontam à tradição wallersteiniana e à sua fundamentação na história econômica. $\mathrm{O}$ texto escolhido, de autoria de Albert Bergesen, explica especialmente a dimensão histórica da ciência a respeito da substituição das perspectivas predominantes na pesquisa internacional, social e educacional pelo paradigma do sistema mundial (Bergesen, 1980).

Nesse trabalho, Bergesen recapitula as mudanças básicas do paradigma que, desde o século XVIII, ganharam aceitação na história da teoria social. Assim fazendo, ele demonstra que cada uma dessas teorias, nas suas mudanças, corresponde a uma inversão do modelo básico da ordem social. Desse modo, ele, de um lado, traça paralelos entre a transição dos (i) modelos interacionistas, baseados no indivíduo, característicos do utilitarismo do final do século XVIII para (ii) as concepções holísticas de ordem, características dos sistemas sociológicos desenvolvidos no final do século XIX e, por outro lado, uma revolução teórica que deve ocorrer 
ao final do século XX. De fato, Bergesen declara que (iii) as formas primitivas do paradigma do sistema mundial, que vêm se desenvolvendo desde a década de 50, no quadro da teoria da dependência, ainda conceberam a inequitativa divisão mundial do trabalho como resultado gradativo das interações — relações de intercâmbio e processos econômicos - entre os estados centrais e as áreas da periferia, isto é, entre um pequeno número de nações altamente industrializadas e um grande número de países mais ou menos desenvolvidos e dependentes. Entretanto, está na hora, de acordo com Begersen, de proceder a uma outra mudança radical na conceituação da origem global e pensar no sistema mundial como (iv) uma realidade emergente sul generis, como uma "realidade coletiva exógena para as nações":

A revolução final do paradigma virá quando invertermos o referencial das partes-para-o-todo da perspectiva do sistema mundial e mudarmos para um paradigma distinto do todo-para-as-partes, que coloca, apriori, relações sociais de produção mundiais, que, por sua vez, determinam as relações de comércio e intercâmbio entre centro e periferia.

Conseqüentemente, o sistema mundial

tem suas próprias leis de movimento que, por sua vez, determinam as realidades socioeconômicas e políticas das sociedades nacionais que o englobam (Bergesen, 1980, p.xiii e 10).

A Sociologia, ciência da sociedade, é, portanto, substituída pela Globologia, a ciência da "realidade coletiva da ordem mundial" (idem, ibidem, p.8).

Será que isto significa que mudou irremediavelmente "a luz das questões centrais da civilização" - mais uma vez relembrando Max Weber? Em outras palavras, será que o direito de representar a modernidade científica, para a qual as ciências sociais, comparadas e humanas, com toda razão, reivindicaram seus direitos no começo do século XIX passou, ao final do século XX, às análises do único sistema mundial 
de inter-relações e interdependências que tenham se intensificado de formas desconhecidas?

\section{Conclusões}

A EMERGÊNCIA DE UM SISTEMA EDUCACIONAL MUNDIAL

Consubstanciar empiricamente os argumentos metacientífícos significa - em complemento a sua historicidade - resolver tais questões, não na hora ou de acordo com as conjeturas especulativas, mas, sim, procurando na pesquisa e considerando cuidadosamente as conclusões e os problemas revelados no processo. Essas descobertas são inesperadamente ricas.

Primeiro, rapidamente enumerarei os principais resultados da pesquisa, que foram apresentados dentro do paradigma do sistema mundial, e que, por sua vez, contribuíram para elaborar mais os modelos do sistema mundial no campo da pesquisa educacional internacional. Esses resultados indicam processos maravilhosos de alinhamento global que ocorreram em níveis diferentes e em diferentes dimensões da educação.

a) Para começar, nas últimas quatro décadas, uma expansão educacional mundial uniformizada abraçou todos os níveis do sistema educacional (Komenan, 1987; Kurian, 1988, p. 15-36). Essa expansão tem sido tão grande e tão uniformizada que não mais pode ser explicada em termos das diversas condições contextuais, demandas sociais ou tendências prevalecentes em ambientes bastante diversos:

Análises estatísticas compreensivas da expansão educacional, incorporação de mulheres, especificação constitucional de direitos e deveres educacionais etc., Ramirez e Boli-Benett resumem, "revelam que as diversas características nacionais tiveram pouco ou nenhum efeito sobre essas variáveis dependentes durante o período do pós-guerra. Daí, há pouco apoio para qualquer das numerosas e muito debatidas teorias que tentam dar conta desse desenvolvimento. Ao invés, oferecemos a visão de que a 
educação tem se tornado um importante elemento do sistema social transnacional (Ramirez, Boli-Bennett, 1982, p.32-33; Meyer et al., 1977).

Comparada ao crescimento educacional em geral, a tendência à expansão é até mais marcante no caso das universidades. A despeito dos divergentes sistemas políticos, níveis de desenvolvimento econômico ou prioridades de políticas públicas dos países individuais, o aumento mundial nas matrículas universitárias apresenta a tendência mais importante do desenvolvimento internacional do pós-guerra (Altbach, 1991c, p. 193; Ramirez, Riddle, 1991).

b) Essa expansão acompanha a aceitação global de um modelo amplamente padronizado de escolarização institucionalizada, como meio de orientar e avaliar políticas educacionais mundiais. Este modelo padronizado é uma combinação das distintas características estruturais do moderno sistema educacional, cujo desenvolvimento europeu no século XIX foi descrito com detalhes como o processo de formação de sistemas ou "sistematização" na pesquisa histórico-comparativa atual (Muller, Ringer, Simon, 1987). A disseminação mundial dessas características estruturais é considerada por muitos um saliente indicador dos processos de globalização cultural (Boli-Bennett, Ramirez, 1992; Ramirez, BoliBennett, 1987). Essas características incluem:

- um referencial administrativo geral, comumente criado, controlado e financiado pelo Estado;

- um sistema escolar internamente diferenciado de acordo com os sucessivos níveis, diversos cursos e exames;

- a organização de processos de ensino e aprendizagem na sala de aula de acordo com a idade e unidades de tempo uniformizadas;

- a regulamentação governamental ou pública de tais processos de ensino e aprendizagem, mediante requisitos mais ou menos detalhados na forma de ementas, diretrizes e provas;

- o estabelecimento de papéis distintos para professores e alunos e, até certo ponto, a profissionalização dos professores e dos métodos de ensino; 
— por fim, o uso de certificados, diplomas e históricos para vincular carreiras escolares às ocupacionais, ligando a seleção escolar á estratificação social.

c) Entretanto, um exame mundial, desenvolvimentista e cultural, e uma ideologia educacional (Fiala, Lanford, 1987) surgiram de forma paralela, apoiaram e reforçaram os processos acima mencionados, de expansão e globalização. Dentro desse esquema, a escolarização institucionalizada é considerada um componente integral, uma alavanca indispensável dos processos de modernização social. As subjacentes idéias programáticas são enraizadas nos princípios orientadores que determinaram a auto-interpretação da modernidade européia desde o século XIX, ou seja: (i) o desenvolvimento da personalidade individual e a competência participativa; (ii) a igualização das oportunidades sociais e políticas; (iii) o desenvolvimento econômico; (iv) uma ordem política garantida pelo Estado-Nação. Essas idéias, por sua vez, são refletidas - na padronização global e com intensidade crescente no tempo - nos objetivos educacionais e nas normas gerais a respeito da infầncia, da família e da educação, que podem ser encontradas nas constituições de um número rapidamente crescente de países de todos os continentes.

d) Finalmente, a disseminação desta semântica da modernização - como também do modelo correspondente da escola moderna (Adick, 1992a) - não teria sido possível sem a infra-estrutura social e institucional provida por uma comunicação internacional e um sistema de publicações no campo das ciências sociais e da educação (Altbach, 1987, 1991a, 1991b e 1994). Isto inclui, por um lado, ampla gama de organizações internacionais comprometidas com o desenvolvimento e a implementação de políticas nas áreas da educação e cultura, tais como o Banco Mundial, Unesco, o Bureau Internacional da Educação, o Instituto Internacional para Planejamento Educacional e a OCDE. Organizações internacionais de grande porte como essas fornecem não apenas definições institucionalmente seguras dos papéis para grandes estabelecimentos educacionais 
internacionais - que em parte se consideram como eminentemente supranacionais (ver, por exemplo, o relato autobiográfico de Hoggart, 1978) - como recursos para publicações e, portanto, oportunidades extraordinárias para distribuição e influência internacional. O sistema científico de comunicação, por outro lado, tem se tornado fortemente hierarquizado entre o centro - hoje quase sinônimo de academia angloamericana - e as áreas periféricas. Um grupo de nações ricas e industrializadas da América do Norte, Europa e Japão e um número de grandes editoras multinacionais, tais como Macmillan, Pergamon, Harper \& Row, Prentice Hall, Elsevier, Hachette ou Bertelsmann, compõem na frase de Philip Altbach (1991b, p.122) — "um tipo de OPEP do conhecimento". Com seu potencial para pesquisa e pessoal acadêmico, e através dos livros de texto e de revistas especializados, as nações ricas e as editoras multinacionais controlam, respectivamente, a produção e a distribuição do que é considerado o relevante conhecimento científico pelo mundo afora. De fato, estudos em certos subcampos da pesquisa educacional produzem evidência suficiente para mostrar como, mesmo as conceituações de problemas, esquemas teóricos, esquemas classificatórios e categorias estatísticas, avaliações de qualidade e padrões normativos de avaliação, que são correntes em organizações internacionais e em círculos acadêmicos anglo-americanos, exerceram pressão sobre os pesquisadores para que eles adaptassem os seus trabalhos a esses critérios - e esta pressão é tanto mais bem-sucedida, na medida em que não for assim percebida (Hüfner, Meyer, Naumann, 1987).

Basta mencionar apenas um exemplo dessa aliança tríplice entre o sistema hierarquizado da ciência, a infra-estrutura internacional de editoração e a disseminação global de uma ideologia especial, desenvolvimentista e educacional. Os autores dos dez volumes da International Encyclopaedia of Education (Husén, Postlethwaite, 1985) são, quase todos, membros do establishment anglo-americano da pesquisa educacional. Dos 1.175 autores, quase a metade $(\mathrm{N}=564)$ vem dos Estados 
Unidos e aproximadamente $75 \%(\mathrm{~N}=855)$ vêm dos países industriais de língua inglesa tomados como um todo. Se acrescentarmos a esses números autores de países como a India, a África do sul ou a Suécia, que cada vez mais usam a língua inglesa como o idioma da comunicação acadêmica, a proporção dos autores que falam inglês aumenta para quase $80 \%$. Um dos redatores-chefes tentou justificar essa dominação anglo-americana pelo peso absoluto da pesquisa americana. De acordo com as suas afirmações, quase a metade da literatura mundial na área da educação foi produzida nos Estados Unidos durante o período de planejamento da enciclopédia. Além disso, mais pesquisadores em educação trabalharam nos Estados Unidos durante esse período do que em todos os países europeus juntos (Husén, 1990, p.68). Apesar da sua autodefinição como sendo internacional, a enciclopédia é, de fato, uma novidade para a disseminação da pesquisa educacional anglo-americana ou influenciada por ela. Portanto, a internacionalização em educação, como em outras áreas, pode ser equivalente apenas à "universalização de um ponto de vista especial mundial" (Casanova, 1993).

A distribuição mundial dessa enciclopédia educacional, em grande escala, é garantida pela capacidade financeira e comercial da Pergamon, que tem filiais em quase todos os continentes e está entre as maiores editoras acima citadas. Publicada pela Pergamon pela primeira vez em 1985, a International Encyclopaedia é comercializada, desde então, na forma de duas edições impressas (Husén, Postlethwaite, 1988 e 1991), um $\mathrm{CD}$ e um número de enciclopédias parciais mais especializadas sobre subáreas selecionadas ${ }^{8}$. Como indicação adicional de sua prevalecência, uma edição de 12 volumes, aumentada e atualizada, foi publicada em

\footnotetext{
' Ver, dentre outras, as seguintes referências: PSACHAROPOULOS, George (Ed.), Economics of education, Research and Studies, 1987; POSTLETHWAITE, T. Neville (Ed.), The Encyclopedia of Comparative Education and National Systems of Education, 1988; KEEVES, John P. (Ed.), Educational Research, Methodology and Measurement: An International Handbook, 1988; THOMAS, R. Murray (Ed.), The Encyclopedia of Human Development and Education, 1990; WALBERG, Herbert, HAERTEL, Geneva D. (Ed.), The International Encyclopedia of Educational Evaluation, 1990; LEWY, Arieli (Ed.), The International Encyclopedia of Curriculum, 1991.
} 
1994. O pròprio sucesso editorial da enciclopédia é, portanto, instrumental à disseminação praticamente ilimitada de uma ideologia supostamente transnacional. De fato, as edições originais e as reimpressas de 1985 a 1991 contêm nada menos que 180 verbetes pertencentes ao planejamento educacional, desenvolvimentista e mundial e à ideologia educacional. Não chegou a ser incluído um verbete sobre "educação", que delinearia sistematicamente a estrutura da educação em si, transcendendo uma mera visão instrumentalista da educação e que, assim fazendo, ligaria a enciclopédia às tradições da teoria educacional prevalecente em partes do mundo, além dos países que falam inglês.

Em face do pano de fundo destas evidências que se corroboram mutuamente, quanto à expansão global da educação, torna-se inteligível a disseminação mundial dos modelos da escola institucionalizada, a aceitação de uma ideologia educacional e desenvolvimentista, o funcionamento da comunicação internacional científica, a estrutura editorial e os diagnósticos originados em outros contextos com base em outras evidências. Um levantamento das diferentes áreas das políticas de pesquisa comparada mostra, de fato, que em nenhuma outra área das políticas públicas, nem nas da economia, das políticas sociais ou ambientais, existe tão alto grau de padronização global das estruturas organizacionais, modelos relevantes (em termos das suas políticas) e discurso reformista, como nas políticas educacionais e na pesquisa educacional, orientadas para as políticas educacionais (Weiler, 1987). Conclui-se que os sistemas educacionais e a pesquisa educacional, diferente das outras áreas da interação social, simplesmente não são um componente fixo dos processos mais generalizados da internacionalização e globalização dos padrões culturais. Ao invés disso, parecem particularmente sensíveis à dinâmica da crescente internacionalização. Portanto, de acordo com a tese formulada em termos parsonianos, "escolas" - no sentido do modelo estrutural — são um "universal evolucionário" do desenvolvimento sociocultural da modernidade (Adick, 1988, p.353, 1992a e 1992b). 
Tendo em mente tais conclusões e conceituações a respeito do emergente sistema mundial, deve-se rever os resultados da própria pesquisa transnacional comparada. Mais precisamente: quais são os resultados da pesquisa social comparada que usa a comparação como método distinto da análise e não apresenta apenas levantamentos descritivos ou interpretações sintéticas dos desenvolvimentos internacionais?

$\mathrm{Na}$ secção seguinte serão resumidos os principais resultados da pesquisa comparada recente em relação às áreas sociais problemáticas, que em países diferentes foram e continuarão a ser caracterizadas por desafios, na maior parte semelhantes às políticas educacionais e sociais. Essas são áreas que, ao mesmo tempo, são e continuarão a ser interpretadas em termos eminentemente universalistas, dentro do quadro de teorias sociais relevantes, áreas estas que, por causa dos modelos prognósticos predominantes, levam a expectativas dos padrões convergentes de solução dos problemas. Estas áreas-problema, são vistas como determinadas por relações causais ou funcionais macrossociais semelhantes a leis. De fato, entretanto, a pesquisa comparada descobriu uma impressionante faixa de variações internacionais, em relação aos padrões de resolução de problemas e de estratégias que se desenvolvem em diversos ambientes históricos e culturais.

a) Tais constatações se aplicam primeiro a todo o complexo das políticas de emprego e do mercado de trabalho, que cada vez mais estão interligadas às políticas sociais e educacionais. Análises comparadas dos resultados das estratégias seguidas para garantir o pleno emprego mostram não apenas que tais estratégias - educação continuada e treinamento para os empregados, políticas para os trabalhadores migrantes, prevenção de danos morais no sistema de seguridade social, flexibilidade salarial etc. — são empregadas em grau consideravelmente variado, mesmo entre as 
nações industriais avançadas, comprometidas com a livre empresa, como também alcançam resultados extraordinariamente diversos (Schmid, Füglistaler, Hohl, 1992). Entretanto, tais estudos relevam uma variação nas medidas do desempenho econômico, nas políticas de adaptação estrutural e nas prioridades da gestão da economia de cada país, para a qual não há, ao contrário das pressuposições das teorias macroeconômicas, "uma única explicação econômica plausível". Enquanto todos os países levados em consideração

foram expostos aos mesmos choques econômicos externos, suas respostas não poderiam ser mais diferentes... Não parece haver nenhuma correlação entre as taxas de crescimento econômico e as taxas de inflação, entre inflação e desemprego, ou mesmo entre crescimento econômico e crescimento de emprego. Ao invés disso, parece que, num contexto econômico mundial em condições cada vez mais negativas, cada país escolhe perfis específicos de desempenho econômico, favorecendo ou ignorando medidas específicas de desempenho (Scharpf, 1984, p.259).

Da mesma forma, a capacidade preditiva das teorias de convergência dos anos 60 - discutindo a convergência evolucionaría dos padrões desenvolvimentistas das modernas sociedades industriais como conseqüência dos imperativos funcionais impostos pelas exigências supostamente universais da racionalidade tecnológica e econômica foi refutada pelas evidências comparadas, apontando para a persistência, nessas mesmas sociedades, de distintos perfis nacionais de organização social e econômica (Goldthorpe, 1984; Kumon, Rosovsky, 1992). Estudos comparados mais recentes mostram como a enorme pressão para incrementar a produtividade é enfrentada em todos esses países por diversas estratégias de inovação, as quais, por sua vez, são enraizadas em políticas claramente divergentes, industriais e do mercado de trabalho (Sabei et al., 1987; Naschold, 1992). Um exemplo disso é o modelo japonês da nova organização do trabalho, conhecido desde os anos 80 como "Toyotismo". Ao invés de seguir simplesmente esse modelo 
supostamente superior e independente dos contextos culturais, os países industriais da Europa e da América do Norte, levando em consideração padrões nacionalmente diferentes de instituições de relações industriais, condições de mercado de trabalho e sistemas educacionais e de treinamento, mostram preferência por diferentes caminhos, com diferentes resultados:

Agora, com o colapso dos regimes comunistas da Europa Oriental, com a integração econômica na Europa Ocidental e com a dominação contemporânea da ideologia do livre mercado, novas teorias de convergência tornam-se tentadoras. Porém, instituições nacionais arraigadas e circunstâncias específicas de mercado tornam a diversidade local e nacional tão importante hoje como nunca (Turner, Auer, 1992, p.28).

b) Extraem-se conclusões semelhantes de uma extensa pesquisa comparada, que trata da interação entre educação profissionalizante e sistemas de treinamento, estruturas de qualificação de mão-de-obra e organização de trabalho em unidades industriais de grande escala. Aprende-se então a desconfiar da tese - colocada pela sociologia industrial e pela economia da educação - que diz que os requisitos de qualificação e as estruturas educacionais e de treinamento são determinadas, na sua maior parte, pela mudança tecnológica, pelo desenvolvimento econômico e pelas exigências de uma racionalidade universal intrínseca ao industrialismo (Maurice, 1980; Heidenreich, Schmidt, 1991). Esses estudos mostraram, mais ainda, que a educação e o treinamento profissional, bem como o uso da mão-de-obra, mesmo nos quadros das sociedades industrializadas tecnologicamente avançadas, são predominantemente definidos por fatores sociais e culturais (ver Dore, 1973;D'lribame, 1989).

Análises comparadas profundas de empresas industriais similares da França, Grã-Bretanha e Alemanha são exemplares destacados dessa corrente da pesquisa. As análises mostram, de modo convincente, que essas empresas, embora muito parecidas em termos de ramo industrial, 
tamanho, produtos, tecnologia da produção e competitividade nos mesmos mercados, mesmo assim estruturam suas respectivas forças de trabalho de acordo com distintos padrões nacionais de organização de empresa e divisão de trabalho. Estes padrões se referem, por um lado, ao aspecto horizontal da divisão de trabalho, isto é, a diferenciação funcional entre os componentes centrados na produção das unidades industriais e nas funções de apoio em áreas de planejamento da produção técnica, administração, estoque e armazenamento, atividades comerciais e, por outro lado, ao seu aspecto vertical, isto é, a diferenciação entre os níveis hierárquicos de trabalhadores, a equipe gerencial intermediária de apoio e a direção. As diferenças nos respectivos padrões de organização de trabalho são especialmente evidentes entre empresas francesas e alemãs. Enquanto empresas francesas, em geral, utilizam sistematicamente uma divisão bem delimitada de trabalho, tanto horizontal como verticalmente, o padrão de organização do trabalho predominante nas empresas alemãs caracteriza-se por um número significativamente menor de níveis hierárquicos de supervisão e de cargos gerenciais; menores diferenças salariais; uma divisão menos rígida de trabalho; grau maior de competência profissionai e técnica entre os chefes de escalões inferiores, supervisores e trabalhadores; e, conseqüentemente, mais amplas oportunidades para a tomada de decisões baseadas em avaliação artesanal e contínuo melhoramento das qualificações profissionais, mesmo entre os trabalhadores envolvidos nas atividades secundárias (Lutz, 1976). As fábricas inglesas são organizadas num padrão que não é menos específico para cada nação e, num certo sentido, intermediário entre os modelos francês e germânico (Maurice, Sorge, Warner, 1980; Sorge, Warner, 1987). Os Kombinats russo-soviéticos, por outro lado, fundamentaram-se sobre padrões de trabalho que, por causa do seu alto grau de diferenciação funcional e hierarquização vertical, ficaram muito mais perto do modelo francês, embora os padrões russos houvessem se desenvolvido em circunstâncias 
sócio-históricas muito específicas (Pietsch, 1980). Afinal de contas, o impacto das "culturas industriais nacionalmente divergentes" (Maurice, Sorge, Warner, 1980, p.65) torna-se evidente, quando se comparam as filiais das empresas transnacionais estabelecidas em vários países e diferentes continentes (Hofstede, 1986; Hirata, 1991).

Em face do pano de fundo destas impressionantes evidências, não é mais possível desconsiderar as variações observadas internacionalmente da organização de empresas de grande escala, simplesmente como deficiência, ou desvio de padrões supostamente universais da racionalidade industrial. A percepção mais profunda, encorajada pela pesquisa comparada, fornece provas conclusivas que há uma estreita interdependência, não modificável arbitrariamente, entre os padrões nacionalmente específicos de organização industrial de trabalho, estruturas de qualificação da força de trabalho, sistemas de educação e treinamento, padrões nacionalmente específicos de mobilidade e progressão de carreiras e instituições de relações industriais. Acima de tudo, são as respectivas instituições de educação e treinamento que desempenham, nesse contexto, um papel especialmente importante. Elas operam como subsistemas, na maior parte autônomos, que, ao influenciarem o seu contexto social, induzem outros subsistemas (como as grandes firmas industriais) a se adaptarem. Assim, o modelo altamente inclusivo de educação e treinamento profissional, baseado na aprendizagem, tradicionalmente predominante na Alemanha, favoreceu, até há pouco tempo, a transmissão ampla da competência tècnico-pràtica, e desse modo, a lateralização da comunicação interprofissional dentro da empresa (por exemplo, entre trabalhadores, supervisores e técnicos), encorajada por esses antecedentes comuns. Em contraste, é característico dos padrões da educação profissionalizante, baseada na escolarização em tempo integral, promover a hierarquização dos cursos e graus correspondentes que, mais tarde, serão reproduzidos na ordenação dos padrões de carreira e posição no emprego. Colocam-se em discussão casos como o da França, onde as estruturas da educação profissionalizante são sujeitas aos critérios de 
seleção de um sistema escolar comprometido com as virtudes da educação geral e do conhecimento abstrato, bem como o da Grã-Bretanha, onde se destaca a ênfase nas noções básicas da ciência e tecnologia experimental, ao invés da especialização prática e profissionai.

As percepções desses estudos comparados revelam interdependências estruturais

entre o grau de profissionalização dos vários grupos de pessoal, ao longo da dimensão de habilidades técnico-práticas, e a tendência a diferenciar tarefas técnicas, gerenciais e de supervisão, tanto na área operacional como na gerencial. Quanto maior a profissionalização prática dos trabalhadores, técnicos, supervisores e gerentes, menores as tarefas técnicas e de chefia separadas do trabalho e organizadas em cargos diferenciados. Da mesma forma, é menor a diferenciação interna. Tais atividades são menos diferenciadas, internamente, na área administrativa. Os fatores desse processo são mais fortes na Alemanha, intermediários na Grã-Bretanha e menos fortes na França (Maurice, Sorge, Warner, 1980, p.81).

Em cada caso mencionado, essas interdependências se desenvolvem como redes de inter-relacionamento que, embora permanecendo consistentes intranacionalmente, variam significativamente, quando examinadas internacionalmente. Essas redes - entre relações de treinamento, relações organizacionais, relações industriais e relações de ordem coletiva - evoluíram, reciprocamente adaptadas uma a outra, e se solidificaram estruturalmente em processos de longo prazo. Tais redes social e culturalmente determinadas do inter-relacionamento, por sua vez, provavelmente determinarão as formas e estruturas diferenciadas da subseqüente utilização das novas tecnologias, mantendo, desse modo, a rica diversidade dos padrões histórico-culturais (Lutz, 1976; Maurice, Sellier, Silvestre, 1979; Deppe, Hoss, 1984).

c) A pesquisa comparada internacional sobre as relações entre educação, modernização e desenvolvimento revela conclusões, na sua maior parte, semelhantes. Um exame desta volumosa pesquisa demonstra que essas relações são consideravelmente mais complexas que as supostas pelas 
teorias de modernização, baseadas na economia da educação, na ciência política, ou na psicologia social (Fàgerlind, Saha, 1985; Grellet, 1992). Isso se aplica ainda mais aos modelos, sugerindo elos causais lineares entre as instituições modernizantes (isto é, escolas ou empresas), valores modernos, comportamento moderno, sociedade moderna e desenvolvimento econômico, que foram construídos tendo em vista sugerir estratégias para políticas desenvolvimentistas (Inkeles, Smith, 1974). Em cada dimensão relevante para as políticas desenvolvimentistas - educação e crescimento econômico, educação e modernização sociopsicológica, educação e mobilização política - , essas relações nem são diretas nem lineares, nem produzem os mesmos efeitos em sociedades diferentes. Ao contrário, via de regra essas relações não são muito pronunciadas e apenas parcialmente eficazes, basicamente disfuncionais ou pura e simplesmente contraproducentes. De qualquer forma, elas são altamente problemáticas e podem ser entendidas apenas em termos dos inter-relacionamentos.

A Educação - no sentido de educação tipo ocidental — é tanto determinada como determinante da sociedade em que se localiza; (...) tanto um agente de mudança como objeto de mudança pela sociedade; (...) A Educação age como produtora da mobilidade social e agente de reprodução da ordem social (Fãgerlind, Saha, 1985, p.88-195).

Essas inter-relações são embutidas e reformuladas por redes de relações sociais mais envolventes. Desse modo, o impacto da educação, que se pode observar em diferentes países, como também as estruturas da modernidade alcançadas em cada um deles, são conseqüências das diversas condições contextuais dominantes em diferentes sociedades, que, por sua vez, influenciam essas mesmas condições contextuais de maneiras diversas.

O que as três correntes da pesquisa comparada têm em comum é que seus resultados demonstram uma multiplicidade observável de várias redes e caminhos desenvolvimentistas. Embora, em geral, essas redes e caminhos desenvolvimentistas possam ser conceituados, no referencial de sistemasmodelo e tipologias sistêmicas, sua complexidade essencial deve ser mais 
elucidada através de análise comparada de longo alcance. As conclusões gerais que poderão ser extraídas dessas correntes de estudos comparados lembram o trabalho de Samuel Eisenstadt em pesquisa histórico-comparada de modernização (Eisenstadt, 1973, p.362). Essas conclusões são também apoiadas pela pesquisa em áreas como política comparada e sociologia comparada de organizações. Este conjunto de pesquisas, em face das evidências obtidas pelo método comparado, comprova a dissolução dos conceitos baseados numa racionalidade supostamente universal do industrialismo (Heidenreich, Schmidt, 1991) e das concepções que presumem uma lógica unidimensional de desenvolvimento (Menzel, 1991). Não apenas o assim chamado Terceiro Mundo - conceito construído dentro do esquema da teoria e da política desenvolvimentista - divide-se numa multiplicidade mai concebida de países em vias de industrialização, países menos desenvolvidos, países mais seriamente afetados, países-limite, países de baixa renda, países exportadores de petróleo versus países importadores de petróleo, países com acesso ao mar versus países sem acesso, países de grande território versus minipaíses e países insulares; não apenas as diversidades culturais das instituições políticas e organizações aumentam cada vez mais, a despeito da antecipada convergência para o modelo universal — digamos, ocidental. Mais que isso, as teorias abrangentes que reivindicam validade universal, sejam baseadas nas teorias da modernização ou dependência, estruturalfuncionalismo ou no marxismo, não mais dão conta da ampla variação do que Humboldt uma vez chamou os "objetos históricos da ciência social". Em outras palavras, a crise do universalismo (Badie, Hermet, 1990, p. 19-44) corresponde ao fracasso das grandes teorias (Menzel, 1991; Boudon, 1992). Não há - resumem os comparatistas franceses — determinantes universais; os processos históricos individuais são muito numerosos, muito complexos e, por isso, independentes uns dos outros ${ }^{9}$.

\footnotetext{
' "Il n'y a pas de déterminismes universels, car les histoires sont, pour cela, trop nombreuses, trop complexes et, en fait, trop indépendantes les unes des autres (Badie, Hermet, 1990, p.10).
} 


\section{Perspectivas}

RECONCILIANDO HISTÓRIA E COMPARAÇÃO

O exame que fizemos dos vários campos da pesquisa social e educacional comparada e internacional mostra um contraste enorme entre a difusão global dos modelos educacionais transnacionalmente padronizados e a persistência das diversas redes de inter-relacionamento sociocultural. Além das informações específicas à nação, esse contraste é o mais significativo resultado da pesquisa comparada e o mais pertinente de todos, o que é relevante para a teoria. A seguir, isto será explanado sistematicamente nos seus três diferentes aspectos.

a) Essa transição para um ponto de vista mais sistemático é facilitada pelos próprios resultados da pesquisa comparada, especialmente aqueles relacionados ao desenvolvimento da educação superior, das ciências (especialmente as ciências sociais) e do sistema internacional.

De fato, esses resultados mostram um alinhamento internacional, dramaticamente crescente, dos processos de expansão e uma homogeneização significativa das características organizacionais. Entretanto, torna-se evidente que a universidade européia é a única instituição (além da escola), cuja disseminação (incluindo o estabelecimento de campi de universidades americanas, francesas e japonesas em outros países) é mais clara e ocorre por falta de alternativas mais do que outras características da modernidade social (Stichweh, 1992, p.5; ver também Altbach, 1991c). Por outro lado, pesquisa recente demonstra que é exatamente a expansão global das universidades em sistemas de grande escala que resulta, não numa convergência crescente, mas numa diferenciação nacional maior. A medida que os sistemas de educação superior perdem suas características elitistas, a evidência sugere que é fortalecida a sua concreta integração aos vários padrões nacionais da estratificação social, da estrutura de qualificação de mão-de-obra, da regulamentação administrativa e das políticas públicas (Goldschmidt, 1991a e 1991b; Kerr, 1991; Teichler, 1988). 
Da mesma forma, evidências têm surgido contrárias nas ciências sociais. Análises comparadas da sociologia do conhecimento mostram a persistência da semântica histórica, baseada na língua nacional, e das culturas acadêmicas impregnadas da tradição, apesar da reivindicação de racionalidade científica universalmente válida (ver Ringer, 1992; Harwood, 1992 e 1993). As análises demonstram, além disso, como certas disciplinas - apesar da intensificação da comunicação internacional entre cientistas - continuam a obter e mesmo renovar suas principais orientações paradigmáticas fora do âmbito das suas respectivas tradições teóricas (ver Schriewer, Reiner, 1992 e 1993, na área dos estudos educacionais; e Schylze, 1989, na área da história). Ademais, como reação à dominação global anglo-americana na área da pesquisa e da disseminação científica (ver Chekki, 1987), o debate tem focalizado recentemente as tendências conflitantes da internacionalização versus indigenização das ciências sociais (Genov, 1989, p.1-17), bem como o desenvolvimento das "sociologías indígenas específicas" a diferentes culturas, em oposição à Ciência Social Universal (Albrow, King, 1990).

Análises de ciência política comparada apresentam conclusões que apontam para um vínculo praticamente dialético entre integração supranacional e fragmentação intranacional (McGrew, 1992, p.23; Smith, 1992). Elas demonstram como as tentativas da integração supranacional, principalmente européia, correm paralelamente não apenas à manutenção, como também ao fortalecimento do Estado-Nação e à extensão e à intensificação da capacidade de domínio (Sharpe, 1989; Milward et al., 1992). As análises apóiam a idéia de que o crescimento dos esforços para realizar a integração transnacional acompanha a dinâmica dos processos de diversificação regional, dinâmica esta expressa lingüística, ética ou culturalmente (Grant, 1981; Charpentier, Engel, 1992; Scardigli, 1993).

A pesquisa comparada em educação superior, ciências sociais e sistema internacional torna evidente que os fenômenos contrários da internacionalização e da elaboração estrutural específica à nação não ocorrem lado a lado, paralelamente, sem nenhuma relação um com o outro. 
De fato, são interligados na forma de desafios e reações, como processos e conseqüências não-intencionais. Referem-se igualmente às relações constituídas no tempo e ao potencial para a diversificação inerente em tais relações; aos processos desenvolvimentistas e à complexidade gerada portais processos. Elas analisam, em outras palavras, a perspectiva macro em relação às áreas de grande escala, englobando processos históricos, o que é uma característica da abordagem do sistema mundial. Desse modo, elas nos isentam de qualquer noção de uma racionalidade unilinear que determina objetivos e que pode ser atribuída a tais processos.

Seria impreciso conceber a globalização como algum tipo de processo teleológico. E inaceitável a idéia de que a globalização incorpora alguma lógica predeterminada, que está levando inexoravelmente ou para a criação de uma sociedade mundial ou para alguma forma de governo mundial, simplesmente. A evidencia histórica é contrária, pois a globalização estimula as forças da oposição, que podem simplesmente levar a um mundo cada vez mais fragmentado, uma vez que a maior conscientização mútua e as interligações entre as sociedades diferentes podem lançar as sementes da discórdia e da tensão (McGrcw, 1992, p.23; Smelser, 1991, p.89).

b) Quando consideradas sistematicamente, também são proveitosas as percepções surgidas das análises dos processos transnacionais de migração, dos estudiosos e dos especialistas, e a difusão e a receptividade das idéias e dos modelos que permeiam, com intensidade cada vez maior, a história européia e, posteriormente, mundial da educação, desde o século XIX. Além de iluminar o caráter carregado de conflitos da internacionalização e da globalização nos seus processos, a vantagem especial de tais análises é que elas mostram os passos intermediários dados pelos atores e/ ou grupos sociais dos quais esses processos são compostos. O significado atribuído a essas análises, ao contrário do papel marginal que lhes é reservado no contexto da educação comparada tradicional, encontra-se no fato de que elas servem de crítica empírica das abordagens teóricas e dos modelos interpretativos comprometidos com a suposta lógica desenvolvimentista histórica mundial. Ao contrário das pressuposições sobre as quais tal lógica 
se baseia, elas destacam bastante a natureza não-linear e contingente dos processos de globalização e do impacto repetidamente provocado nesses processos por potenciais geradores de desvios. Caracteristicamente, a difusão transcultural do conhecimento, dos modelos organizacionais, dos padrões de resolver problemas ou políticas, é enfrentada pelos grupos culturais receptores com procedimentos de reinterpretação e adaptação. Conseqüentemente, os modelos oferecidos transculturalmente são, neste novo ambiente, selecionados de acordo com os interesses maiores, adaptados às específicas situações e necessidades, reinterpretadas através das linhas culturais e - em graus historicamente variados - transmutadas em novas formações estruturais.

A dimensão mundial da universidade no estilo europeu, citada antes, a história das ciências sociais e a difusão dos princípios ocidentais da ordem política e da organização do Estado oferecem muitos exemplos desses procedimentos adaptadores. Comparações, por exemplo, entre Brasil e Japão, mostram que a recepção e a implementação institucional do modelo da universidade européia, em países não-europeus, seguiram padrões bastante diferentes, apesar dos desafios similares da modernização. As pré-condições de cada um desses países, como as respectivas capacidades de penetração dos sistemas políticos, a presença variada das elites modernizadoras, os padrões predominantes da estratificação social e a estrutura das instituições educacionais existentes destacaram-se decididamente nesses processos. Por exemplo, no Japão, a seleção de elementos ecléticos, tirados de vários modelos de universidade (principalmente francês, americano e alemão), bem como a sua subordinação à modernização e aos requisitos de qualificação definidos por governos autoritários, levaram a uma transformação adaptadora uma indigenização - dos modelos ocidentais, enquanto imunizavam as universidades imperiais japonesas contra os sintomas indesejáveis e os efeitos percebidos nos exemplos estrangeiros. Por outro lado, no Brasil, a fraqueza relativa das elites modernizadoras e industriais favoreceu $\mathrm{o}$ atraso da cultura e a dominação ideológica da influência francesa em geral, 
assim como a tradição francesa da manutenção de faculdades independentes, Grandes Écoles, em especial nas áreas de medicina, engenharia, economia, agricultura, ciências militares e ciências naturais. Também essas circunstâncias correspondem a uma dependência científica e econômica moderada das potências estrangeiras até a metade do século XX (Cowen, 1988). Conclusões da história da ciência apóiam conclusões semelhantes. Mesmo uma visão superficial da pesquisa — desde a divulgação da filosofia e da filologia alemãs do século XIX pela Europa (Espagne, Werner, 1988 e 1990) à adoção da sociologia weberiana na França, Estados Unidos e Sudoeste da Ásia (Pollak, 1986; Kantowsky, 1982), até a gênese da moderna pedagogia no Japão, introduzida por um teórico herbartiano, há muito esquecido na Alemanha (Terasaki, 1989) —, mostra a recepção das teorias e inovações científicas para formar uma série interminável de interpretações e reinterpretações peneiradas pelos interesses prevalecentes e canalizados para constelações preexistentes de discursos. Pode-se dizer que a mesma coisa vale para a disseminação dos princípios democráticos ocidentais e das respectivas instituições políticas em países não-ocidentais (Badie, 1992a). Como no exemplo japonês, as instituições adotadas, de modo meramente formal, são mescladas a comportamentos políticos, significados sociais e padrões específicos de exercício de autoridade preexistentes. Nesse processo de reestruturação "num sistema sem âmago" dentro de um cerne, essas instituições mudam seu significado e sua maneira de funcionar (Wolferen, 1989).

A multidão de lógicas de adaptação sugerida por esses exemplos e o esquema cultural subjacente gerador de desvios, de diferentes noções de tempo e de verdade, e as experiências coletivas sedimentadas no curso da história

desmascararam as visões altamente ideológicas, proclamando o fim da história (devido à convergência supostamente irresistível a favor do modelo ocidental da sociedade capitalista liberal) como uma pura ilusão. Tal reivindicação pode se referir a fenômenos superficiais e à impressão da ocidentalização, ameaçando certos processos de transmissão. Atrás disto, na realidade, 
dissimula-se um complexo jogo de empréstimos e apropriações, como também o reaparecimento de maneiras populares de ação política e culturas antigas que o comparatista é obrigado a levar em consideração: os caminhos da China, índia e Japão são feitos de pura aparência, à medida que absorvem apropriações e a reatualização das milenarias tradições culturais ${ }^{10}$.

As percepções da pesquisa comparada sobre a complexidade dos processos de difusão e recepção podem ser combinadas imediatamente com conclusões igualmente complexas, previamente detalhadas em relação à divulgação global dos modelos educacionais, transnacionalmente padronizados, por um lado, e à persistência das diversas redes de interrelacionamento sociocultural, por outro. Para concluir em termos gerais, existe um universalismo abstrato dos modelos transnacionalmente disseminados, que se difundem em padrões estruturais multiformes, sempre que tais modelos interagem, no curso da implementação institucional, com diferentes esquemas definidos pelos Estados, regulamentos administrativos e legais, formas da divisão de trabalho na sociedade, culturas acadêmicas nacionais, significados sociais limitados pelo contexto e visões mundiais religiosas. Em outras palavras, a escola como um universal evolucionário aparece não tanto como sendo universal, mas como socioculturalmente particular, tão logo se analisam sistematicamente as múltiplas inter-relações entre as credenciais eduionais e os privilégios conferidos por elas; entre a realização educacional e o sucesso na carreira; entre a educação e o emprego; entre a seleção pelas escolas e a estratificação social; entre as estruturas da escola e do direito público; entre o estudo na universidade e o ethos coletivo; entre os processos de aprendizagem e a mudança social e entre a racionalidade científica e o momento auto-evolutivo da semântica histórica.

\footnotetext{
10 "... réduisent au pur état d'illusion les visions très idéologiques proclamant la fin de l'histoire. Celles-ci peuvent à la riguer s'appliquer aux phénomènes de surface et à l'impression d'occidentalisation qui se dégage de certains processus d'importation. Derrière cette vitrine, se dissimulent en réalité un jeu complexe d'importations et d'appropriations, mais aussi de résurgences de modes populaires d'action politique et de cultures très anciennes dont le comparatiste se doit de tenir compte: les trajectoires chinoise, indienne ou japonaise sont tout autant faites de purs plaques que d'appropriations mesurées et d'actualisations de traditions culturelles millénaires" (Badie, 1992b, p.366-367).
} 
Tais referências ao Estado, ao direito, à cultura e às experiências coletivas, às visões do mundo mediadas pela religião, pela língua nacional e pela semântica histórica indicam o potencial de amplificar e gerar desvios que deram origem, historicamente, a novas configurações socioculturais. Sistematicamente, essas referências reatualizam também as percepções das contribuições duradouras da pesquisa social comparada de Lorenz von Stein (1868) a Stein Rokkan (1970); de Max Weber (1920-1921) a Pierre Birnbaum (1988); e de Norbert Elias (1978) a Ernest Gellner (1988).

c) Com esses antecedentes, as metodologias divergentes, discutidas no início do debate educacional comparado - contrastando orientações nomotéticas e idiográficas; abordagens orientadas por variáveis e aquelas orientadas por casos; ou, em outras palavras, contrastando um paradigma positivista, usando a comparação como procedimento quase experimental, para testar a teoria com um paradigma historicista, enfatizando a explanação globalizante dos fenômenos ou configurações culturalmente definidos apresentam-se como sendo consideravelmente menos irreconciliáveis que aquelas retratadas por seus respectivos proponentes. De fato, esses distintos contrastes se nivelam até o ponto onde a Educação Comparada e a sua pesquisa aceitam o desafio suscitado pela perspectiva macrohistórica que tomou forma na resposta aos processos de globalização e das abordagens do sistema mundial. Enfrentar esse desafio significa, além de identificar as relações específicas entre as variáveis e, complementar as configurações socioculturais, historicamente reconstruídas, e incorporar tanto procedimentos metodológicos em análises globalizadas da modernização social de grande escala, quanto a difusão transcultural e os processos de recepção.

Sugere-se tal ampliação da perspectiva analítica após nossa peneiração dos resultados das diversas áreas da pesquisa comparada; de fato, isto se nos impõem pelo próprio entrecruzamento das correntes contrárias

— da internacionalização e da indigenização;

— da integração supranacional e da diversificação intranacional; 
— do universal evolucionarlo e das configurações socioculturais;

- dos processos de difusão global e dos processos de recepção específicos à cultura;

- de um universalismo abstrato dos modelos transnacionalmente disseminados e da elaboração estrutural geradora de desvios; e

— da divulgação global dos modelos educacionais padronizados (a despeito do ambiente social) e a surpreendente diversidade das redes de inter-relações socioculturais (apesar das pressuposições de grandes teorias).

É esse o labirinto, então, que demarca o terreno comum, onde as questões de escolarização, educação e treinamento se encontram, em termos práticos e políticos, com o que Max Weber chamava de "questões centrais da civilização", num mundo em fase de mudança. Entretanto, essa mistura de correntes contrárias significa um núcleo de problemas inevitáveis de análise empírica e de explanação teórica para a qual a Educação Comparada é convocada a resolver. Esses problemas explicativos formam o contexto em que a Educação Comparada, até o final do século XX, será obrigada a levar em consideração, quando se prepara, como diria Weber, (i) para clarificar suas linhas mestras orientadoras, (ii) explicar suas abordagens metodológicas e (iii) identificar seu esquema conceitual. Isto pressupõe que a Educação Comparada como área se recuse a responder aos ciclos de curta vida das políticas educacionais ou a ser substituída sem protesto pelas pretensões de uma ciência mundial emergente (Globologia), que se define - como o ideal do fim do século XVIII sugeriu, e como as mais recentes considerações reivindicam - como disciplina que analisa aspectos específicos compassadamente (em oposição à sistemática ou histórica) de uma Ciência da Educação como tal (Diemer, 1970).

As conseqüências dessas conclusões, no nível da prática científica, são três. A Educação Comparada, que pretende dar todo o relevo à complexidade do seu domínio, não tem nenhuma escolha a não ser (i) conceituar seu objeto em perspectiva, igualmente em termos das trajetórias 
da modernização social, das configurações socioculturais e da difusão transcultural e dos processos receptivos (ver McMichael, 1990) ${ }^{11}$. Como conseqüência dessa junção de perspectivas, a pesquisa comparativa tornase associável às teses dos teóricos do sistema mundial. Da mesma forma, a pesquisa comparada contribui para a elucidação empírica, por meio de detalhadas reconstruções históricas do caráter globalizante dos processos de internacionalização, e verifica (por meio das comparações metodológicas) a validade da reivindicação do universalismo evolucionário. Nessa mistura de perspectivas, a Educação Comparada é compelida (ii), metodologicamente, a reconciliar história e comparação em paralelo com o consenso crescente que emergiu do debate em sociologia histórica (Badie, 1992b, p.364). Essa reconciliação não é uma mera fusão da comparação transcultural e das análises do processo histórico na pesquisa históricocomparativa (Schriewew, 1984), mas também implica a temporalização dos próprios conceitos explicativos (definições de problema, variáveis de pano de fundo, configurações causais etc.) e modelos analíticos (ver Castles, 1989). Finalmente, essas conseqüências enfatizam orientações teóricas e sistemas conceituais que são capazes de incorporar a gama considerável de pontos de vista metodológicos, perspectivas analíticas e uma pesquisa correspondente de informações. Isto significa que os sistemas são capazes de integrar as perspectivas, geradas nos diversos campos da pesquisa comparada, em redes de inter-relacionamento e dinâmica de sistemas, mecanismos amplificadores de desvios e causalidade complexa e uma elaboração estrutural e dependência de mudanças estruturais das estruturas prévias.

\footnotetext{
" O conceito da modernização não é usado aqui no sentido de uma ocidentalização inerente a uma lógica supostamente inevitável da história mundial. Serve como um rótulo guarda-chuva (abrangente), como uma "expressão funcional dos processos interligados de mudança secular social, politica, econômica e cultural, lais como industrialização, democratização, burocratização e urbanização, cujos efeitos são sentidos pelo mundo afora, embora de forma altamente igual. (... ) Assim, modernização não implica uma emergência de algum tipo de sociedade mundial na qual homogeneidade ou cosmopolitismo prevalecem. Mesmo porque seus efeitos são desigualmente sentidos e porque promovem resistência onde aparecem. Seria mais preciso concluir que a modernização reforça as tendências à integração e à desintegração do sistema global contemporâneo" (McGrew, 1992, p.25-26).
} 
Teorias que tanto incorporam como elaboram essas perspectivas foram desenvolvidas com base na pesquisa das ciências naturais, das ciências da vida e das ciências sociais, durante as últimas duas décadas. Com tais títulos, como auto-organização ou morfogênese, as teorias delineiam um programa de pesquisa interdisciplinar de crescente importância (ver Krohn, Küppers, Pastlack, 1987); não apenas informam a pesquisa em campos diferentes como meteorologia, teoria da administração e desenvolvimento urbano, como inspiraram reorientações teóricas na pesquisa tecnológica comparada, na sociologia industrial e organizacional e na sociologia comparada da educação. Os principais autores, representantes desses desenvolvimentos teóricos, incluem Margaret S. Archer (1982 e 1985), escrevendo em inglês, Edgar Morin ( 1981 -1985), em francês, e em alemão, Niklas Luhmann (1970-1990 e 1984). Gostaria de discutir aqui somente alguns aspectos desses desenvolvimentos teóricos, não menos porque estão voltados para uma abordagem da história da ciência, mas porque apresentam certos paralelos com os problemas anteriores, enquanto, ao mesmo tempo, oferecem novas respostas.

Semelhante ao final do século XVIII, "o grande programa" da ciência comparada, modelo de auto-organização, aparece no âmbito das ciências da vida. Porém, o significado particular da teoria de Luhman, dos sistemas sociais auto-referenciais, emerge da apropriação das idéias fundamentais da teoria geral de sistemas, da cibernetica, da neurofisiologia, da teoria da comunicação e, ao mesmo tempo, da reformulação desses conceitos com referência à peculiaridade, na frase de Wilhem von Humboldt, do âmbito social. Desse modo, Luhmann elabora precisamente as diferenças entre os sistemas vivos e os sistemas geradores de significados, entre sistemas psíquicos (constituídos na base da conscientização) e sistemas sociais (constituídos na base da comunicação) (Lipp, 1987). Desse modo, a problemaiique de Humboldt, emergindo do antagonismo - inerente à especialidade do objeto-domínio social - entre supostas leis da natureza humana e da energia espontânea do homem, é dada como uma resposta compatível com a ciência social dos dias de hoje. 
Uma vantagem adicional da obra de Luhmann (1975b) surge da mesclagem da teoria dos sistemas com a teoria evolucionaría ou, mais especificamente, da teoria da comunicação com a teoria da diferenciação social $^{12}$. O esquema oferece a ferramenta conceitual para captar tanto a especificidade das áreas socioculturais de ação, por exemplo, a educação, como suas relações com o ambiente social (ver Schriewer, 1987 e 1990b). Ademais, oferecem as opções para tornar compreensíveis essas áreas de ação ou subsistemas, na sua evolução, dentro do contexto dos processos de diferenciação sociohistórica mais abrangente, incluindo a intensificação contemporânea mundial social da comunicação especializada.

Esse quadro teórico torna possível uma conceituação da pesquisa histórico-comparada, que é complexa o suficiente para permitir a análise dos supostos "universais evolucionários", não de modo abstrato e sim de modo historicamente concreto. Isso significa que esse quadro é embutido em processos de diferenciação social, interação social e difusão global, além de tornar possível retomar linhas opostas de interpretação, que permearam as disciplinas comparadas em desenvolvimento, desde o seu início no final do século XVIII. De fato, a oposição entre as abordagens evolucionário-genealógica e ecológico-culturalista — personificada na histórica disputa da Académie em 1830 entre o evolucionista Etienne Geoffroy Saint-Hilaire (apoiado publicamente por Goethe) e o teórico de catástrofes, Georges Cuvier — foi neutralizada, mais tarde, com o eclipse do Saint-Hilaire pelas metodologias científicas que davam prioridade a Cuvier.

\footnotetext{
${ }^{12}$ O leitor deve lembrar-se da distinção e do significado teórico que havia sido acertado, entre outros, por Schluchter (1979), entre as filosofias da história da tradição Hegel-Marx-Toynbee e as mais recentes reformulações da teoria evolucionista, trabalhadas por Luhmann, entre outros. As primeiras são enraizadas na idéia da necessidade causal e constróem seqüências universalmente válidas das fases desenvolvimentistas. As segundas baseiam-se na contingência causal e na causalidade atribuída e reconhecem apenas seqüências das fases reconstruídas a posteriori. Renunciam aos critérios do desenvolvimento e à possibilidade de uma periodização universalmente válida de mudança sociohistórica.
} 
Os conceitos orientadores de auto-referência, reflexividade e reflexão, que fazem parte da teoria de Luhmann, são fundamentais para o desenvolvimento de uma argumentação final. Eles definem os processos socioculturais baseados em significados como uma realidade social que se descreve e se observa e que utiliza esta autodescrição para se organizar. Em essência, esses conceitos, desde o começo, implicam uma perspectiva da sociologia do conhecimento ${ }^{13}$. Essa perspectiva emerge em resposta à disjunção entre os desenvolvimentos estruturais e semânticos, como também às inter-relações que não variam arbitrariamente entre eles nas áreas específicas da ação social, como, por exemplo, educação. As interrelações assumidas, assim, entre estruturas da sociedade e semântica (Gesellschaftsstruklur und Semanlik, Luhmann, 1980-1989), entre padrões da ordem social e os significados correspondentes registrados por escrito, e entre organizações e idéias, fornecem um esquema explicativo para aquelas conclusões da pesquisa comparada, que dá ênfase à importância dos esquemas interpretativos, aos significados sociais (Ringer, 1979) e às capacidades de manutenção e transformação da ordem das dimensões simbólicas da atividade humana (Einsenstadt, 1989), em vários processos de formação de sistemas e de modernização. Servem, então, como elo conceitual adequado para a recombinação — de acordo com Ringer, 1992 — da história social e da história intelectual.

De maior importância, essas inter-relações convidam a uma atenção renovada para uma distinção, estabelecida por Friedrich Schneider, que pode servir para outras análises dos processos da internacionalização. A distinção entre "Educação Internacional" (como área de atividade intelectual) e "interligação internacional em educação" (como fato histó-

\footnotetext{
${ }^{13} \mathrm{O}$ leitor pode referir-se às excelentes traduções em inglês dos ensaios de Luhmann (1982b e 1990). O próprio Luhmann, no capítulo introdutório do primeiro volume (1980-1989), clarifica a sua posiçSo na sociologia do conhecimento, especialmente em relação a Marx e Mannheim.
} 
tórico), mencionada anteriormente, é, de fato, aplicável à diferenciação entre níveis, que pode ser inferida ao longo deste trabalho, por exemplo, a diferença entre um "universalismo abstrato dos modelos transnacionalmente disseminados" e os "padrões estruturais multiformes", que serão agora focalizados. Amplamente independente da internacionalização factual dos padrões típicos de organização e expansão educacional, já foi e continua sendo discutida a "internacionalidade" no debate sobre a reforma educacional. Com conceitos tais como "modelos mundiais" ${ }^{14}$, "padrões internacionais"15, ou "tendências globais de desenvolvimento" ${ }^{16}$, a discussão tende a antecipar o fato da internacionalização. Em outras palavras, o domínio dos processos socioculturais (caracterizados pela complexidade e designados pelos termos "internacionalização" e "modernização") deve ser distinguido do domínio do discurso educacional (que não apenas reflete estes processos como também assume vida própria e se sobrepõe a eles). Esta é a diferenciação entre as duas abordagens analíticas. A primeira foi desenvolvida na seção anterior pela redefinição das perspectivas de uma Ciência de Educação Comparada, em termos iguais às dimensões do problema do seu dominio-objeto. O que agora deve ser especificado, além desta definição e complementado-a, é o enfoque conceitual da análise da sociologia do conhecimento das contribuições pedagógicas à construção semântica da sociedade mundial. A teoria da auto-referência (ou, mais precisamente, a seqüência dos conceitos da "reflexão", "interrupções em relação à interdependência" e à "externalização") oferece a ferramenta conceitual para essa análise.

\footnotetext{
" Um exemplo é a recente tentativa de autores como Chalkere Haynes(1994) para construírem um modelo de Escolas Mundiais.

" Hanf (1980) oferece um relatório breve a respeito de uma reforma de longo alcance projetada para adaptar a educação primária em Ruanda às condições concretas da vida rural e de trabalho da maioria das pessoas. A reforma falhou devido à insuperável resistência de funcionários públicos comprometidos com "padrões internacionais".

" Mesmo a identificação sistemática e a síntese das tendências de desenvolvimento transnacionais, utilizadas como meio de orientar as políticas educacionais, foram transformadas numa abordagem metodológica peculiar à Educação Comparada por Rosselló (1978).
} 
Informado por esses conceitos, um novo exame sociohistórico dos próprios produtos da Educação Comparada institucionalizada complementa a análise empírica dos fenômenos sociais mundiais ${ }^{17}$. Atrás desta abordagem, há um pressuposto de que a teoria educacional se desenvolve, principalmente, não como teoria científica, produzida de acordo com o compromisso da ciência pura com o critério da verdade, mas como teoria da reflexão formulada dentro de cada um dos subsistemas especializados para incentivar a autocompreensão e a capacidade autogestora desses sistemas. A teoria educacional é, assim, a reflexão da teoria do sistema educacional desenvolvida dentro do sistema educacional. Ao discutir seu domínio-objeto, a própria teoria educacional discute o componente do seu domínio-objeto. Ao fazê-lo, ela realiza sua própria autodiscussão. Como todas as formas do fechamento auto-referencial, as teorias de reflexão, desenvolvidas nos contextos dos subsistemas especiais, estão precisando das interrupções das relações circulares de interdependência. Essas interrupções tomam a forma típica dos sistemas, abrindo-se aos seus respectivos ambientes. Através da incorporação do significado suplementar que se possa extrair dos pontos externos de referência, a auto-referência circular torna-se apta a ser especificada.

Para a educação - concebida como teoria da reflexão do sistema educacional —, Luhmann e Schorr (1979, p.338), sem pretenderem ser exaustivos, identificaram três padrões principais da "externalização" apelo (i) aos princípios gerais da racionalidade científica, apelo (ii) aos valores e (iii) à organização. Os autores clarificam as funções que essas formas de externalização desempenham em relação à estabilização da educação como centro do conhecimento teórico, comprometidos tanto com as agendas-problema do sistema educacional como preocupados com o status acadêmico e a reputação. Desse modo, a referência (i) aos

\footnotetext{
${ }^{17}$ Os parágrafos seguintes são tirados de uma linha de raciocínio desenvolvida com maiores detalhes em Schriewer (1990a, p.62) e em extensas referências bibliográficas. Aqui se referem à correspondente literatura, de uma forma resumida.
} 
princípios gerais formulados pelas filosofias da ciência dispensa a educação, a priori, da necessidade de atender ao estabelecimento de pressupostos para validar a sua suposta natureza científica. A referência (ii) a valores, ou ideologias baseadas em valores, externaliza a justificativa para a ação, especialmente no que se refere à reforma educacional e à política da tomada de decisões. Finalmente, a referência (iii) à organização, atribuindo os fracassos à política ou à administração, destaca uma abordagem à qual atribui os mais agradáveis aspectos da realidade social (Luhmann, Schorr, 1979, p.341). Constitui uma característica do pensamento educacional que externaliza desapontamentos e, ao mesmo tempo, estimula a busca de alternativas em organizações educacionais.

Essas características estruturais, relacionadas à natureza autoreferencial da teoria reflexiva, montaram o palco para o exame sociológico e a reinterpretação da maior parte da literatura educacional que, fraca em termos de metodologia comparada e questionável em termos da relevância de construção teórica, é designada convencionalmente como Educação Comparada. De fato, a essa literatura é concedido um novo (e inesperado) significado. Atende à necessidade estrutural para a externalização intrínseca à teoria reflexiva, especialmente no caso de reflexão reformada sobre a educação. Do ponto de vista interno, de um dado sistema de educação, e comprometido com as preocupações práticas do sistema, as referências aos "exemplos no exterior", as "experiências mundiais", ou as "situações mundiais" são, de fato, entendidas mais como histórias contemporâneas da educação, tal com é praticada em outros países. Essas referências devem servir de lição por oferecerem idéias estimuladoras e novo impulso para a definição de políticas, ao delinear um quadro de referências para a especificação de opções para a reforma. $\mathrm{O}$ ato de "olhar, além da sua fronteira, para países comparáveis" é, portanto, concebido em termos especialmente indicativos da pretendida absorção do significado suplementar, através da externalização, como uma "abertura do próprio sistema... aos estímulos externos" (Schorb, 1970, p. 16 e 20). 
Esse tipo de referencia a exemplos no exterior e ao suposto reino da internacionalidade - sem explicitação em termos de teoria e metodologia - pode ser considerado como uma forma de apelo ao ambiente externo, que é complementar aos três padrões de Luhmann e Schorr de externalização. Essas externalizações às situações mundiais relevantes à educação envolvem, assim, não uma análise comparada das diferenças socioculturais perseguidas com a intenção de promover o conhecimento das ciências sociais, como também envolvem a minimização dessas diferenças, sugerindo uma orientação, primeiro no nível das idéias e modelos reformadores e depois no nível das políticas práticas, para as "sociedades de referências" internacionais (Bendix, 1978), sejam estes os países que estão à frente da civilização mundial, como o autor espanhol afirmou no século XIX (Pedro, 1987, p. 163) ou, em termos do final do século XX, "os dez países de classe mundial" (Chalker, Haynes, 1994). Desse modo, eles se baseiam nos termos da distinção de Friedrich Schneider, não no método da análise transnacional, usado como uma abordagem diferente para a construção e/ou explicação de teorias. Mais do que isso, procuram alcançar uma "contemplação transnacional", perseguida com a intenção de expor os principais problemas, idéias e correntes da educação mundial. Em outras palavras, a adequação da externalização às situações mundiais, para produzir significados complementares, relaciona-se não ao uso dos métodos de comparação da ciência social (cujo potencial inerentemente crítico limita-se às complexas técnicas de estabelecer relações ou padrões entre as interligações) e, sim, ao seu recurso ao próprio substituto da comparação, à sua "perspectiva internacional" (organizada de acordo com a discreção do observador, com base nas operações "simples" de identificar semelhanças ou discernir as relações mais/menos, mais cedo/mais tarde, entre os fatos observáveis).

Relatos históricos do desenvolvimento dos estudos comparados e/ou internacionais em educação comprovam isso. Quer preocupadas com a extensão dos ideais da educação progressiva num movimento para a 
educação mundial ou com a identificação com uma idéia européia ocidental de educação; quer percebendo estruturas educacionais como dependentes da convergência das sociedades industrializadas ou numa contínua revolução técnico-científica; quer seja um debate que depende da democratização ou compreensão, da valorização da educação ou das perspectivas mundiais da educação de adultos, todas essas formas do discurso internacional de reforma e politicas educacionais foram desenvolvidas dentro de ambientes nacionais especiais, que

têm servido tanto para apoiar o compromisso dos individuos que pensam de maneira igual, que compartilham dos posicionamentos em questão, como para uma justificativa contra a oposição. Demonstrar a internacionalidade das próprias demandas de reforma significa defendê-las contra a acusação de serem parciais e qualificá-las como universais e indispensáveis (Zymek, 1975, p. 348).

Assim, a externalização às situações mundiais, num sentido, objetiva as justificativas, baseadas em valores para politicas de reforma. Este desempenho justificatório realiza-se na forma das descrições históricas e/ ou de levantamento estatístico, os quais se reconhecem como sendo científicos. Entretanto, como boa parte da literatura internacional de reflexões reformadoras focaliza-se na definição e no desenvolvimento adicional de estruturas institucionais e modelos da organização educacional, este padrão de referir-se à externalidade pela indicação de possiveis alternativas é bem projetado para superar o desapontamento que educadores encontram pela frente, repetidamente, num mundo social determinado pela organização. A externalização (iv) às situações mumdiais, em outras palavras, neutraliza a obrigação do recurso direto (ii) aos valores ou a ideologias baseadas em valores e reitera a referência aos (i) principios da ciência e reforça a externalização (iii) para a organização. Assim, combinando aspectos justificativos, básicos e atribuidos, as externalizações às situações mundiais oferecem um grau significativo de dinamismo autoregulado para uma reflexão reformadora da educação. Conseqüentemente, 
como é aparente tanto nas ambigüidades iniciais implícitas no programa metodológico de Friedrich Schneider como nos desenvolvimentos posteriores desta área, é o tipo de teorização específica para a própria reflexão do sistema educacional que, renovada periodicamente, transformou o programa abrangente da Educação Comparada na sua forma substituta, a Educação Internacional.

Externalizações às situações mundiais não são construídas no vácuo. Ao invés disso, estão incluídas na realidade global — o imenso sistema, de acordo com a corrente institucionalista da pesquisa dos sistemas mundiais (Ramirez, Boli-Bennett, 1987) —, que é caracterizada tanto por sua diferenciação, em diversos sistemas políticos territorialmente organizados, como por múltiplos grupos de inter-relações de competição, rivalidade, conflito, dominação, cooperação ou aliança entre esses sistemas. Os impulsos competitivos, surgindo da operação deste sistema entre Estados, implicam a multiplicação de externalizações de situações mundiais, junto com perspectivas distintas de sistemas/ambientes que correspondem a numerosos sistemas educacionais, definidos em termos de Estado-Nação, e a sistemas relacionados a sistemas de reflexão reformadora sobre a educação. Um contexto, definido em termos políticos e lingüísticos, de auto-reflexão externaliza para outros sistemas educacionais suas auto-reflexões; por sua vez, esses contextos referemse a outros e, assim, compõem modelos e oferecem idéias estimuladoras.

Do acúmulo de relações de observação transistêmica e de externalizações desta natureza, emerge uma teia de referências recíprocas, que assume vida própria, movimentando, reforçando e dinamizando a universalização mundial das idéias, modelos, padrões e opções educacionais para reforma. Esta teia se incorpora - como componente essencial - num discurso auto-sustentado em nível mundial. Afinal, visto da perspectiva da sociologia do conhecimento, este discurso transnacional atua como contrapartida semântica dos futuros processos evolucionários, motivados por uma inquietude dinâmica, intrínseca à sociedade moderna, 
funcionalmente diferenciada, na medida em que esta reage, como construção semântica da sociedade mundial, sobre as estruturas sociais, no sentido de harmonização, padronização e homogeneização.

\section{Referências bibliográficas}

ADICK, Christel. Schule im modernen Weltsystem. Zeitschrift für Kulturauslausch, v.38, n.3, p.343-355, 1988.

Schóningh, 1992a.

Die Utiiversalisierungder modernen Schule. Paderborn:

Historisch-vergleichende Bildungsforschung und die Entwicklungslogik der'langen Wellen'der Schulgeschichte. In: ADICK, Ch., KREBS, U. (Eds). Evolution, Erziehung, Schule: Beitrãge aus Anthropologie, Entwicklungspsychologie, Humanethologie und Padagogik. Erlangen: Universitátsbibliothek, 1992b. p.251-267.

ALBROW, Martin, KING, Elizabeth (Eds). Globalization, knowledge and society. London: Sage, 1990.

ALTBACH, Philip G. The ktiowledge context: comparative perspectives on the distribution of knowledge. Albany: State University of New York Press, 1987.

Textbooks: the international dimension. In: APPLE, M.W., CHRISTIAN-SMITH, L. (Eds). The Politics of the textbook. New York: Routledge, 1991a. p.242-258.

Third world publishers and the international knowledge system. Logos, n.2/3, p. 122-126, 1991 b.

Patterns in higher education development. Prospects, v.21, n.2, p. 189-203, 1991c. 
ALTBACH, Philip G. International knowledge networks. In: HUSÉN, T., POSTLETHWAITE, T.N. (Eds). The international encyclopedia of education. 2.ed. Oxford: Pergamon-Elsevier, 1994. v.5 p.2993-2998.

ANWEILER, Oskar. Comparative education and the internationalization of education. Comparative Education, v.13, n.2, p. 109-114, 1977.

Die Internationale Dimension der Padagogik. In:

ANWEILER, O. Wissenschaftliches Interesse und poli fische Verantwortung: Dimensionen vergleichender Bildungsforschung. Opladen: Leske \& Budrich, 1990. p.225-235.

ARCHER, Margaret S. The sociology of educational expansion: take-off, growth and inflation in educational systems. Berverly Hills: Sage, 1982. p. 3-64 Theorizing about the Expansion of Educacional Systems.

Structuration versus morphogenesis. In: EISENSTADT, S.N., HELLE, H.J. (Eds). Macro-sociological theory. Berverly Hills: Sage, 1985. p.58-88. v.1 Perspectives on sociological theoroy

ARNOVE, Robert. Comparative education and world-systems analysis. Comparative Education Review, v.24, n.1, p.48-62, 1980.

BADIE, Bertrand. L Etat importé. Essai sur l'occidentalisation de l'ordre politique. Paris: Fayard, 1992a.

Analyse comparative et sociologie historique. Revue Internationale des Sciences Sociales, n.122, p.363-372, auôt 1992b.

BADIE, Bertrand, HERMET, Guy. Politique comparée. Paris: PUF., 1990.

BENDIX, Reinhard. Kings or people. Power and mandate to rule. Berkeley: University of California Press, 1978. 
BERGESEN, Albert. Studies of the modern world system. New York: Academic Press, 1980. p.xiii-xiv: Preface, p. 1-12:From utilitarianism to globology: the shift from the individual to the world as a whole as the primordial unit of analysis.

BIRNBAUM, Pierre. States and collective action: the European experience. Cambridge: Cambridge university Press, 1988.

BOLI-BENNETTI, John, RAMIREZ, Francisco O. Compulsory schooling in the western cultural context. In: ARNOVE, R.F., ALTBACH, Ph. G., KELLY, G.P. (Eds). Emergent issues in education: comparative perspectives. Albany: State University of New York Press, 1992. p.25-38.

BOLI-BENNETTI, John, RAMIREZ, Francisco O., MEYER, John W. Explaining the origins and expansion of mass education. In: ALTBACH, Ph. G., KELLY, G.P (Eds). New approaches to comparative education. Chicago: University of Chigago Press, 1986. p.105-130.

BORNSCHIER, Volker, LENGYEL, Peter (Eds). World society studies. Frankfurt: Campus, 1990. v.1

BOUDON, Raymond. Grandeur et décadence des sciences du développement: une étude de sociologie de la connaissance. L'Année Sociologique, 3e série, v.42, p.253-274, 1992.

BRAUDEL, Fernand. Civilisation matérielle, économie et capitalisme: XVe-XVIIIe siècle. Paris: A. Colin, 1979. 3v.

CASANOVA, Pascale. La world fiction: une fiction critique. Liber Revue Européenne des Livres, p. 111 -115, déc. 1993. 
CASTLES, Francis G. (Ed.). The comparative history of public policy. Cambridge: Polity Press, 1989. p.1-15:Introduction.

CHALKER, Donald M, HAYNES, Richard M. World class schools, new standards for education. Lancaster: Technomic Publishing, 1994.

CHARPENTIER, Jean, ENGEL, Christian (Eds): Les régions de l'espace communautaire. [Nancy]: Press Universitaires de Nancy, 1992.

CHEKKI, Dan A. American sociological hegemony, transnational explorations. Lanham: University Press of America, 1987.

COOMBS, Philip H. The world crisis in education, the view from the eighties. New York: Oxford University Press, 1985.

COWEN, Robert. The importation of higher education into Brazil and Japan. In: CUNNINGHAM, P., BROOK, C. (Eds). Proceedings of the 1987 Annual Conference of the History of Education Society held jointly with B.C.I.E.S. Evington: History of Education Society, 1988. p.4149international currents in educational ideas and practices.

CUVIER, Georges de. Leçons d'anatomie comparée. Paris, 1800-1805. 5v.

DEPPE, Rainer, HOSS, Dietrich (Eds). Work organization, incentive systems and effort bargaining in different social and national contexts. Frankfurt: Institut fur Sozialforschung, 1984.

DIEMER, Alwin. Zur Grundlegung eines allgemeinen Wissenschaftsbegriffs. Zeitschriftfür Allgemeine Wissemchaftsheorie, n.2, p.209-227, 1970.

DIERKES, Meinolf, WEILER, Hans N, ANTAL, Ariane Berthoin (Eds.). Comparative policy research, learning from experience. Aldershot: Gower, 1987. 
D'IRIBARNE, Philippe. La logique de l'honneur: gestion des entreprises et traditions nationales. Paris: Seuil, 1989.

DORE, Ronald. British factory — Japanese factory: the origins of national diversity industrial relations. Berkeley: University of California Press, 1973.

DRAGER, Horst. Der interessierte Blick in die Fremde. In: FRIEDENTHALHAASE, M. (Ed). Erwachsenenbildung im ;Context: Beitràge zur grenzüherschreitenden Konstituierung einer Disziplin. Bad Heilbrunn: Klinkhardt, 1991. p.208-225.

DURKHEIM, Emile. Les règles de la méthode sociologique.22.éd. Paris: PUF., 1986.

EISENSTADT, Shmuel N. Tradition, change, and modernity. New York: Wiley-lnterscience, 1973.

Structure and history. International Political Science Review, v.10, n.2, p.99-110, 1989.

ELIAS, Norbert, líber den Prozeâ der Zivilisation. Frankfurt: Suhrkamp, 1978. p. 1-64:Zur Soziogenese der Begriffe "Zivilisation" und "Kultur".

EPSTEIN, Erwin H. Currents left and right: ideology in comparative education. Comparative Education Review, n.27, p.3-39, 1983.

ESPAGNE, Michel, WERNER, Michael. Présentation. Revue de Synthèse IVe série, n.2, P. 187-194, avr./juin 1988.

(Dir.). Philologiques I. Contribution à l'histoire des disciplines littéraires en France et en Allemagne au XIXe siècle. Paris: Maison des Sciences de l'Homme, 1990. 
FÀGERLIND, Ingeniar, S AHA, Lawrence J. Education an national development: a comparative perspective. Oxford: Pergamon, 1985.

FAHLE, Klaus. Die Politile der Europàischen Gemeinschaft in den Bereichen Erziehung, Bildung und Wissenschaft. Gutachten der MaxTraeger-Stiftung. Frankfurt: Max-Traeger-Stiftung, 1989.

FAURE, Edgar. The world of education today and tomorrow. Paris: UNESCO; London: Harrap, 1972. cap.:Learning to be.

FEUERBACH, Anselmvon. Kleine Schrij"ten vermischtenlnhalts. Nürnberg: Otto, 1833. p.152-177:Blick auf die teutsche Rechtswissenschaft. Ed. original de 1810 .

FIALA, Robert, LANFORD, Audri G. Educational ideology and the world educational revolution, 1950-1970. Comparative Education Review, v.31,n.3, p.315-332, 1987.

GELLNER, Ernest. Plough, sword and book. London: Collins Harvill, 1988.

GELPI, Ettore. Conscience terrienne: recherche et formation. Firenze: McColl, 1992.

GENOV, Nikolai (Ed). National traditions in sociology. London: Sage, 1989.

GOLDSCHMIDT, Dietrich. Idealtypische Charakterisierung sieben westlicher Hochschulsysteme. Zeitschriftfür Sozialisationsforschung undErziehumgssoziologie, v.11, n.1, p.3-17, 1991a.

Historische, internationale Vergleiche, globale

Perspektiven. Weinheim: Deutscher studienverlag, 1991b. cap.:Die gesellschaftliche Herausforderung der Universitat. 
GOLDTHORPE, John H. The end of convergence: corporatist and dualist tendencies in modern western societies. In: GOLDTHORPE, John H. (Ed.). Order and conflict in contemporary capitalism. Oxford: Clarendon, 1984. p.315-343.

GRANT, Nigel. European unity and national systems. In: SIMON, B., TAYLOR, W. Education in the eighties: the central issues. London: Batsford Academic, 1981. p.92-110.

GRELLET, Gérard. Pourquoi les pays en voie de développement ont-ils des rythmes de croissance aussi différents? Revue Tiers Monde, v.33, n. 129, p.31-66, 1992.

HANF, Theodor. Die Schule der Staar soligarchie. Bildung und Erziehung v.33, n.5, p.407-432, 1980 .

HARWOOD, Jonathan. A study of the German genetics community: 19001933. Chicago: University of Chicago Press, 1992. cap.:Styles of scientific thought.

."Mandarine" oder "AuBenseiter"? Selbstverstàndnis

deutscher Naturwissenschaftler (1900-1933)". In: SCHRIEWER, Jurgen, KEINER, Edwin, CHARLE, Christophe (Orgs). Sozialer Raum und akademische Kulturen. A la recherche de l'espace universitaire européen. Frankfurt: Lang, 1993. p.183-212

HASSELT, Jutta Von, SCHOFTHALER, Traugott. Die Weltkonferenz der Erziehungsminister geràt in Bewegung. UNESCO-Dienst, v.36, n.1/2, p.9-14, 1989.

HEIDENREICH, Martin, SCHMIDT, Gert (Orgs). International vergleichende Organisationsfor-schung. Fragestellungen, Methoden und Ergebnisse ausgewàhlter Untersuchungen. Opladen: Westdeustscher, 1991. 
HJRATA, Helena Sumiko. Brasilien, Frankreich, Japan: Unterschiede und die Suche nach Bedeutung. In: HEIDENREICH, Martin, SCHMIDT, Gert (Orgs.). International vergleichende Organisationsfor-schung. Fragestellungen, Methoden und Ergebnisse Untersuchungen; Opladen: Westdeustscher, 1991.p. 180-189

HOFSTEDE, Geert. Culture's consequences: international differences in work-related values.2.ed. London: Sage, 1986.

HOGGART, Richard. An idea and its servants. Unesco within. London: Chatto \& Windus, 1978.

HÜFNER, Klaus, MEYER, John W., NAUMANN, Jean. Comparative education policy research: a world society perspective. In:

DIERKES, Meinolf, WEILER, Hans N, ANTAL, Ariane Berthoin (Eds.). Comparative policy research: learning from experience. Aldershot: Gower, 1987. p. 188-243

HUMBOLDT, Wilhelm von. Schriften zur Anthropologie und Bildungslehre. Org. Andreas Flitner, 2. Auflage. Dusseldorf: Küpper, 1964. p.32-59:Plan einer vergleichenden Anthropologic

HUSÉN, Torsten. Education and the global concern. Oxford: Pergamon, 1990.

HUSÉN, Torsten, POSTLETHWAITE, T. Neville (Eds). The international encyclopedia of education. Research and Studies. Oxford: Pergamon, 1985. 1Ov. Reimpressão em 1988 e 1991.

INKELES, Alex, SMITH, David H. Becoming modern. London: Heinemann, 1974.

INKELES, Alex, SIROWY, Larry. Convergent and divergent trends in national educational systems. Social Forces, v.62, n.2, p.303-333, 1983. 
JULLIEN DE PARIS, Marc-Antoine. Esquisse et vues préliminaires d'un ouvrage sur l'éducation comparée. Paris: Colas, Delaunay, 1817.

KANTOWSKY, Detlef. Die Rezeption der Hinduismus/BuddhismusStudie Max Webers in Südasien. Ein Missverstàndnis. Archives Européennes de Sociologie, v.23, n.2, p.317-355, 1982.

KATZ, Joseph. Chronologie de l'Année Internationale de l'Education et du Conseil Mondial des Sociétés d'Education Comparée. Conseil Mondial des Sociétés d 'Education Comparée: Bulletin, v.6, n.1, p.6-11, 1978.

KERR, Clark. International learning and national purposes in higher education. American Behavioral Scientist, v.35, n.1, p. 17-22, 1991.

KOMENAN, Andre G. World education indicators. Washington: Worldbank, 1987. (Education and training series report, n. EDT 88).

KONIG, René (Org). Handbuch der empirischen Sozialforschung, 3, umgearbeitete \& erewiterte Aufl. Miinchen: dv \& Enke, 1974). cap.4:KomplexeForschungsansatze.

KROHN, Wolfgang, KÜPPERS, Günther, PASLACK, Rainer. "Selbstorganisation: Zur Genèse und Entwicklung einer wissenschaftlichen Revolution. In: SCHMIDT, S.J. (Ed.). Der Diskur des Radikalen Konstruktivismus. Frankfurt: Suhrkamp, 1987. p.441-465.

KRUGER, Bernd. Bildungswesen und Padagogik im Prozess ihrer Inlernationalisierung. Münster: Pádagogiche Hochschule Westfalen Lippe, 1974.

KUMON, Shumpei, ROSOVSKY, Henry (Eds). The political economy of Japan. Stanford: Stanford University Press, 1992. v.3:Cultural and social dynamics. 
KURIAN, George Thomas (Ed). World education encyclopedia. New York: Facts on File, 1988. 3v.

LEFMANN, S. Franz Bopp, sein leben und seine Wissenschaft, 2. Halite. Berlin: Georg Reimer, 1895.

LIPP, Wolfgang. Autopoiesis biologisch, Autopoiesis soziologisch. Kõlner Zeitschrift für Soziologie und Sozialpsychologie, n.39, p.452-470, 1987.

LUHMANN, Niklas. Soziologische Aufklarung. Opladen: Westdeutscher, 1970-1990. 5v.

Gesellschaftsstruktur und Semantik. Studien zur Wissenssoziologie der modernen Gesellschaft. Frankfurt: Suhrkamp, 1980-1989. 3v.

Soziologische Aufklarung 2. Opladen: Westdeutscher, 1975a. p.51-71:Die Weltgesellschaft.

Opladen: Westdeutscher, 1975b. p. 193203:Systemtheorie, Evolutionstheorie und Kommunikationstheorie.

The world society as a social system. International Journal of General Systems, v.8, n.3, p. 131-138, 1982a.

The differentiation of society. New York: Columbia University Press, 1982b.

Soziale Système: Grundriss einer allgemeinen Théorie. Frankfurt: Suhrkamp, 1984.

Press, 1990 .

Essays on self-reference. New York: Columbia University 
LUHMANN, Niklas, SCHORR, Karl-Eberhard. Reflexiomprobleme im Erziehungssystem. Stuttgart: Klett-Cotta, 1979.

LUTZ, Burkart. Bildungssystem und Beschàftigungsstruktur in Deutschland und Frankreich. Zum EinfluB des Bildungssystems auf die Gestaltung betrieblicher Arbeitskràftestrukturen. In: MENDIUS, H.-G (Ed). Betrieb-Arbeitsmarkt-Qualifikationl. Frankfurt: Aspeke, 1976. p. 83-151.

MAURICE, Marc. Le déterminisme technologique dans la sociologie du travail (1955-1980). Un changement de paradigme?" Sociologie du Travail v.22, n.1, p.22-37, 1980.

MAURICE, Marc, SELLIER, François, SILVESTRE, Jean-Jacques. La production de la hiérarchie dans l'entreprise: comparaisons FranceAllemagne. Revue Française de Sociologie, v.20, n.2, p.331-365, 1979.

MAURICE, Marc, SORGE, Arndt, WARNER, Malcolm. Societal differences in organizing manufacturing units: a comparison of France, West Germany, and Great Britain. Organization Studies, v. 1, n. 1, p. 5986, 1980 .

MCGREW, Anthony G. Conceptualizing global politics. In: MCGREW, Anthony G., LEWIS, Paul G. et al. Global politics, globalization the nation-state. Cambridge: Polty \& Blackwell, 1992. p. 1-28.

MCGREW, Anthony G., LEWIS, Paul G. et al. Global politics: globalization the nation-state. Cambridge: Polty \& Blackwell, 1992. p. 1-28.

MCMICHAEL, Philip: "Incorporating Comparison within a WorldHistorical Perspective: An Alternative Comparative Method", in American Sociological Review, n.55, p.385-397, 1990. 
MENZEL, Ulrich. Das Ende der "Drintten Welt" und das Scheitern der groBen Teorien. Politische Vierteljahresschrift, v.32, n. 1, p.4-33,1991.

MEYER, John W. et al. The world educational revolution, 1950-1970. Sociology of Education, n.50, p.242-258, 1977.

MEYER, John W., HANNAN, Michael T. (Eds). National development and the world system, educational, economic, and political change, 1950-1970. Chicago: Chicago University Press, 1979.

MILWARD, Alan S. et al. The European rescue of the nation-state. London: Routledge, 1992.

MORIN, Edgar. La méthode.nouv.éd. Paris: Seuil, 1981-1985. t.I: La nature de la nature; t.2: La vie de la vie.

MULLER, Detlef K., RINGER, Fritz, SIMON, Brian (Eds). The rise of the modern educational system. Cambridge: Cambridge University Press; Paris: Maison des Sciences de PHomme, 1987.

MULLER-S OLGER, Hermann. Bildungspolitische Zusammenarbeit der Europãischen Gemeinschaft in Europa. Zeitschriftür Padagogik, v.36, p.805-825, 1990.

NASCHOLD, Frieder. Dean Wandel organisieren. Erfahrungen schwedischen Entwicklungsprogramms"Leitung, Organisation, mitbestimmung" (LOM) im internationalen Werbewerb. Berlim: Sgima, 1992.

PARSONS, Talcott. Evolutionary universais in society. American Sociological Review, v.29, p.339-357, 1964.

PEDRO, Frances. Los precursores españoles de laeducación comparada. Antologia de textos. Madrid: Universidad Nacional de Educación a Distancia, 1987. 
PETERSON, A.D.C. The international baccalaureate. an experiment in education. London: Harrap, 1972.

PIETSCH, Anna-Jutta. Die Interdependem von Qualifikationsbedarfund Arbeitsorganisation. untersucht am Beispiel der Sowjetunion im Verleich mit Frankreich, der Bundesrepublik Deutschland und der DDR. München: Osteuropa-Institut, 1980.

POLLAK, Michael. From methodological prescription to socio-historical description. Fundamenta Scientiae, v.4, p. 1-27, 1983.

. Die Rezeption Max Webers in Frankreich. Fallstudie eines Theorietransfers in den Sozialwissenschaften. Kôlner Zeitschrift für Sozialpsychologie, v.38, n.4, p.670-684, 1986.

POSTLETHWAITE, T. Neville (Ed). Special issue on the Second IEA Study. Comparative Education Review, v.31, n.1, 1987.

PSACHAROPOULOS, George. Critical issues in education. Washington: Worldbank, 1987. (A world agenda, education and training series report, n.EDT 96).

RAMIREZ, Francisco O., BOLI-BENNETT, John. Global patterns of educational institutionalization. In: ALTBACH, Ph. G., ARNOVE, R.F., KELLY, G.P (Eds). Comparative education. New York: Macmillan, 1982. p. 15-36.

RAMIREZ, Francisco O., BOLI-BENNETT, John. The political construction of mass schooling: European origins and worldwide institutionalization. Sociology of Education, n.60, p.2-17, 1987.

RAMIREZ, Francisco O., RIDDLE, Phyllis. The expansion of higher education. In: ALTBACH, Ph. G. International higher education: an encyclopedia. New York: Garland, 1991. v.1 p.91-105. 
RINGER, Fritz K. Education and society in modern Europe. Bloomington: Indiana University Press, 1979.

Fields of knowledge. French Academic Culture in comparative perspective, 1890-1920. Cambridge: Cambridge University Press; Paris: Maison des Sciences de l'Homme, 1992.

ROKKAN, Stein et al. Citizens, elections, parties. Approaches to the comparative study of the processes of development. Oslo: Universitetsforlaget, 1970.

ROSSELLO, Pedro. La teoria de las corrientes educativas: Cursillo de Educación Comparada Dinámica.2.ed. Barcelona: Ed. Promoción Cultural, 1978.

S ABEL, Charles F et al. Regional prosperities compared. Massachusetts and Baden-Württemberg in the 1980s. Berlin: Wissenschaftszentrum Berlin fur Sozialforschung, 1987.

SCARDIGLI, Victor (Dir). LEurope de la diversité: la dynamique des identités régionales. Paris: CNRS, 1993.

SCHARPF, Fritz W. Economie and institutional constraints of fullemployment strategies: Sweden, Austria, and Western Germany. In: GOLDTHORPE, J.H. Order and Conflict in Contemporary Capitalism. Oxford: Clarendon, 1984. p.257-290.

SCHLUCHTER, Wolfgang. Die Entwicklng des okzidentalen Rationalismus: Eine Analyse von Max Webers Gesellschaftsgeschichte. Tübingen: Mohr, 1979.

SCHMID, Hans, FÜGLISTALER, Peter, HOHL, Marcela. Vollbescháftigungspolitik: Der Wille zum Erfolg. Ein Làndervergleich der Schweiz, Deutschlands, Õsterreichs, Schwedens und Japans. Bern: Haupt, 1992. 
SCHNEIDER, Friedrich. International Padagogik, Auslandspadagogik, Vergleichende Erziehungswissenschaft. Internationale Zeitschriftfür Erziehungswissenschaft, v.1, p. 15-39,243-257,392-407, 1931/1932; V.2, p.79-89, 1932/1933.

SCHORB, Alfons Otto. Der internationale Vergleich as Instrument der Bildungspolitik. In: HILLIGEN, W., RAASCH, R. (Eds). Pàdagogische Forschung undpàdagogischer Fortschrit. Bielefeld: Bertelsmann, 1970.

SCHRIEWER, Jurgen. Erziehung'und "Kultur". Zur Théorie und Methodik Vergleichender Erziehungwissenschaft. In: BRINKMANN, W., RENNER, K. (Eds.). Die Padagogik un ihre Bereiche. Paderbon: Schóningh, 1982. p. 185-236.

Vergleichend-historische Bildungsforschung:

Gesamttableau oder Forschungsansatz? Zeitschrift für Padagogik, v.30, n.3. p.323-342, 1984.

Funktionssymbiosen von Überschneidungsbereichen:

Systemtheoretische Konstrukte in vergleichender Erziehungsforschung. In: OELKERS, J., TENORTH, HE. (Eds). Padagogik, Erziehungswissenschaft und Systemtheorie. Weinheim\& Basel: Beltz, 1987. p.76-101.

The method of comparison and the nee for externalization: methodological criteria and sociological concepts. In: SCHRIEWER, J., HOLMES, B. (Eds). Theories and Methods in Comparative Education.2.ed. Frankfurt: Lang, 1990a. p.25-83.

Comparación y explicación en el análisis de los sistemas educativos. In: PEREYRA, M.A. Los usos de la comparación en ciencias sociales y en educación. Madrid: Centro de Publicaciones del MEC, 1990b. p.77-127. 
SCHRIEWER, Jurgen, KEENER, Edwin. Communication patterns and intellectual traditions in educational sciences: France and Germany. Comparative Education Review, v.36, n.1, p.25-51, 1992.

Kommunikationsnetze und Theoriegestalt: Zur

Binnenkonstitution der Erziehungswissenschaft in frankreich und Deutschland. In: SCHRIEWER, Jurgen, KEENER, Edwin, CHARLE, Christophe (Orgs). SozialerRaum undakademische Kulturen. A la recherche de l'espace universitaire européen. Frankfurt: Lang, 1993. p.277-341.

SCHREEWER, Jurgen, KEENER, Edwin, CHARLE, Christophe (Orgs.). Sozialer Raum und akademische Kulturen. A la recherche de l'espace Universitaire européen. Frankfurt: Lang, 1993.

SCHULZE, Winfried. Deutsche Geschichtswissenschaft nach 1945. München: Oldenbourg, 1989.

SHARPE, L. J. Fragmentation and territoriality in the European state system. International Political Science Review, v.10, n.3, p.223-238, 1989.

SMELSER, Neil J. Internationalization of social science knowledge. American Behavioral Scientist, v.35, n.1, p.65-91, 1991.

SMITH, Michael. Modernization, globalization and the nation-state. In: MCGREW, Anthony G., LEWIS, Paul G. et al. Global politics. globalization the nation-state. Cambridge: Polty \& Blackwell, 1992. p.253-268.

SO, Alvin Y. Social change and development, modernization, dependency, and world-system theories. Newbury Park, London: Sage, 1990.

SORGE, Arndt, WARNER, Malcolm. Comparative factory organization. an Anglo-German comparison of management and manpower in manufacturin. Aldershot: Gower, 1987. 
STEIN, Lorenz Von. Das Elementar-und das Berufsbildungswesen in Deutschland, England, Frankreich und anderen Làndern. Die Verwaltungslehre. Fünfter Theil: Die Innere Verwaltung. Zweites Hauptgebiet: Das Bildungswesen. Stuttgart: Cotta, 1868.

STICHWEH, Rudolf. Zur Entstehung des modernen Systems wissenschaftlicher Disziplinen. Physik in Deutschland 1740-1890. Frankfurt: Suhrkamp, 1984.

A uslatidssludien in der Moderne —Eine strukturelle Analyse. Beitrag fur das internationale Colloquium iiber Modèles nationaux, réseaux transculturels et réseaux migratoires dans le monde universitaire européen, XIXe-XXe siècles. Ruhr-Universitát Bochurn, 14-18 Nov. 1992.

TEICHLER, Ulrich. Convergence or growing variety, the changing organization of studies. Strasbourg: Council of Europe, 1988.

TENBRUCK, Friedrich H. Emile Durkheim oder die Geburt der Gesellschaft aus dem Geist der Soziologie. Zeitschriftfür Soziologie, n.10, p.333-350, 1981.

TERASAKI, Masao et al. Oyatoi Kyoshi Emil Hausknechl no Keukyu. Tokyo: University of Tokyo Press, 1989.

TURNER, Lowell, AUER, Peter. The political economoy of new work organization. Different roads, different outcomes. Berlin: Wissenschaftszentrum Berlim für Sozialforschung, 1992.

UNESCO. World Conference on Education for All: catalogue of documents. Paris, 1992.

WALLERSTEIN, Immanuel. The modern world system: capitalist agriculture and the origins of the Europen world economy in the sixteenth century. New York: Academic Press, 1976. 
WALLERSTEIN, Immanuel. Unthinking social science: the limits of nineteenth-century paradigms. Cambridge: Polity Press, 1991.

WEBER, Max. Gesammelte Aufsàtze zur Religionssoziologie. Tübingen: Mohr/Siebeck, 1920-1921. 3v. 6.ed.1978; 7.ed.1983.

Gesammelte Aufsàtze zur Wissenschqfrslehre.4 ed.

Tübingen: Mohr, 1973. p.146-214:Die "Objektivitàt" sozialwissenschaftlicher und sozialpolitischer Erkenntnis.

WEILER, Hans N. Introductory note to chapters 8-9. In: WEILER, BERTHOINANTAL, 1987. p. 186-187.

WOLFEREN, Karl van. The enigma of Japanese power: people and politics in a stateless nation. New York: Alfred A. Knopf, 1989.

ZYMEK, Bernd. Das Ausland als Argument in der padagogischen Reformdiskussion. Ratingen: Henn, 1975. 